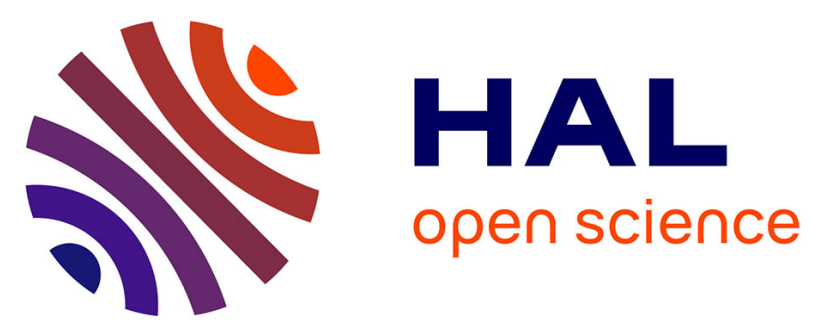

\title{
Low prices cum selective distribution versus high prices: how best to signal quality?
}

Nada Ben Elhadj, Didier Laussel

\section{To cite this version:}

Nada Ben Elhadj, Didier Laussel. Low prices cum selective distribution versus high prices: how best to signal quality?. Applied Economics, 2017, 49 (44), pp.4440 - 4459. 10.1080/00036846.2017.1284988 . hal-01658369

\section{HAL Id: hal-01658369 \\ https://hal-amu.archives-ouvertes.fr/hal-01658369}

Submitted on 7 Feb 2022

HAL is a multi-disciplinary open access archive for the deposit and dissemination of scientific research documents, whether they are published or not. The documents may come from teaching and research institutions in France or abroad, or from public or private research centers.
L'archive ouverte pluridisciplinaire HAL, est destinée au dépôt et à la diffusion de documents scientifiques de niveau recherche, publiés ou non, émanant des établissements d'enseignement et de recherche français ou étrangers, des laboratoires publics ou privés.

\section{(1) (1) $\$$}

Distributed under a Creative Commons Attribution - NonCommercial - NoDerivatives $\mid 4.0$ 


\title{
Low prices cum selective distribution versus high prices: how best to signal quality?
}

\author{
Nada Ben Elhadja and Didier Laussel ${ }^{\mathrm{b}}$
}

anstitut Supérieur de Gestion de Tunis, University of Tunis, Tunis, Tunisia; ${ }^{\text {b} G r o u p e m e n t ~ d e ~ R e c h e r c h e ~ e n ~ E ́ c o n o m i e ~ Q u a n t i t a t i v e ~ d ' A i x-~}$ Marseille, Centre National de la Recherche Scientifique, de l'École des Hautes Études en Sciences Sociales, Aix-Marseille Université (AMSE)

\begin{abstract}
We investigate the best signalling strategy for a monopoly introducing a new product with unobservable quality when second-period sales are linked to first-period ones and the firm may tailor its distribution network to exclude some consumers. When producing a high quality product rather than a low quality one is relatively costly with respect to the increase in quality, optimal signalling is by price alone. But when the cost differential is lower, it will be optimal to set a low first-period price, not to serve all would-be consumers at this price (selective distribu-tion) and raise the price afterwards. Paradoxically, this strategy allows a larger customer base to be reached than in the case of pure price signalling.
\end{abstract}

KEYWORDS

Quality signal; selective distribution; price signal; increasing/decreasing cost of quality

JEL CLASSIFICATION L12; L15; M37

\section{Introduction}

Selective network distribution is a common practice for suppliers of luxury products in order to enhance the brand image and the perceived quality of their products. Luxury automobiles, Patek Philippe watches, speciality products such as haute couture, Montblanc pens and Fendi handbags are available in very few outlets. There also are prominent examples of high-technology firms choosing selective distribution networks for their new products. For example, the launch of Apple's iPhone was made only in AT\&T and Apple retail stores in the USA. ${ }^{1}$ In France, the iPad was not in the shops of the mobile operators but only in some outlets such as FNAC, Darty and Surcouf and on their websites.

This practice is generally considered to be a signalling strategy on the part of a monopoly firm that launches a new high quality experience product. $^{2}$ Rational consumers are supposed to understand that a low quality firm, benefiting from lower unit costs and hence from a higher unit profit margin, would suffer more from a limitation of sales than the high quality one it attempts to mimic. ${ }^{3}$ If the restriction of sales necessary to emulate a high quality firm $(\mathrm{H})$ is severe enough, a low quality one (L) will prefer to appear as such rather than seek to fool consumers. In so doing, it commands a lower price and profit margin but is able to sell to (much) more consumers. Accordingly, upon noticing that they are in a small number, buyers correctly conclude that the new product is a high quality one. While perfectly relevant, this argument is however not sufficient in itself to explain why all people willing to buy at the posted price should not be allowed to. Sales could be limited only by posting high enough prices and so reducing the number of buyers. It is not in general necessary to exclude some consumers who would derive a positive surplus from buying the good. In a one-period setting, it is easy to show that signalling only by price is the high quality firm's best strategy. If at equilibrium some wouldbe consumers were not served, the high quality firm could raise its price, provided it reduces simultaneously, in due proportion, its sales so that a low quality firm continues not to mimic it. Given that this price increase raises the high quality firm's margin proportionately more than the low quality one, H's profits would rise. This amounts to saying that there is nothing in a one-period setting to mitigate the profit margin effect.

CONTACT Nada Ben Elhadj nadabelhadj@yahoo.com 241 , Avenue de la Liberte, Cite Bouchoucha, Le Bardo 2000, Tunisia

${ }^{1}$ http://www.apple.com/pr/library/2007/06/28iPhone-Premieres-This-Friday-Night-at-Apple-Retail-Stores.html

${ }^{2}$ See for instance Franklin and Faulhaber (1990); Bandyopadhyay, Dongy, and Qinz (2010); Kim (2002); Stock and Balachander (2005).

${ }^{3}$ This is known as the 'profit margin effect'. 
In order to better understand why a firm may find it optimal to restrict sales below the (at least potential) demand level, a two-period model is therefore needed. Such a model has to differ from a oneperiod one, i.e. there has to be a link between the periods: the first-period signalling strategy must have an impact on the second-period outcomes. In our model, the consumers do not initially know the quality of the product while, in the second period, they have learnt it, either from direct experience or by word of mouth. Nevertheless, the firm cannot always implement what would (absent any quantitative constraint) be its full-information best (output, price) strategy as we assume that the initial sales level limits future one(s). ${ }^{4}$ This constraint occurs because increasing the quantities supplied takes a long time and/or is very costly, or because demand itself is 'viscous'. This has a greater effect on the type of firm having the higher full-information output, i.e. on the firm which has the lower cost/quality ratio. Due to this differential impact, a 'sales constraint effect' is present that will be shown to mitigate or even to reverse partially the profit margin effect, so that it may become profitable to exclude some would-be consumers. We indeed suppose here that the firm may choose, in order to signal a high quality, to sell its product only to a subset of consumers, those who have a preference for quality above some threshold. This is done either by setting a high enough price and serving all consumers willing to buy at that price or by selecting exclusive distribution channels ${ }^{6}$ and not serving some consumers (because they are not informed or because the good is not made available to them). In the latter case, the firm may for instance choose to sell its product exclusively only in some outlets and/or in some areas which are only visited by the consumers who are more willing to pay for quality. ${ }^{7}$

In this framework, we show that the firm may find it worthwhile to set a low first-period price and to serve only part of the consumers who would derive a positive surplus from buying the good at that price, rather than to signal by a high price alone, associated with a smaller volume of sales in both periods. The former strategy somewhat paradoxically allows the high quality firm to enlarge its customer base, as compared with the case of signalling only by price. This is admittedly at the cost of a low first-period price, which is to render mimicry by the low quality firm unlikely, but the firm is then able in the second period to raise its price and to reap the benefits of its higher consumer base. This is all the more beneficial as the differential between the second-period maximum prices which may be posted by the two firms is higher, this difference being itself the greater the more substantial is their quality differential. So this 'rationing strategy', which bears some resemblance to introductory pricing, is, for a given differential between the firms' unit costs, intuitively more profitable the higher their quality differential.

A good example of this strategy may be Lexus, the Toyota's luxury auto-brand which, while being of premium quality, was launched at a low price and gained a very large share in the US market for luxury cars, despite a selective distribution. ${ }^{8}$ Lexus, whose prices were initially very low, raised them subsequently on the US market in the 1990s to above the prices of US luxury auto-brands. This strategy was possible because 'Toyota's supply chain capabilities and low-cost assembly know-how allowed it to incorporate high-tech performance features and upscale quality into Lexus models'. ${ }^{9}$ Another candidate is Amazon, which marketed its tablet Kindle at a low price to a wide audience. Dave Limp, president of Amazon's Kindle business, said the company has increased production of the devices in conjunction with the overseas launch. The cost of making the tablets has fallen with greater economies of scale, allowing Amazon to cut prices, he said. ${ }^{10}$ Finally, one can also mention Vizio, a company which sells very high quality flat panel LCD and plasma TVs at low prices. It keeps costs relatively low by manufacturing in Thailand and having a major stakeholder,

\footnotetext{
${ }^{4}$ This assumption may be relaxed. Our qualitative results are unaffected provided future sales depend on initial ones.

${ }^{5}$ See Radner (2003) for a discussion of the many reasons for the viscosity of demand.

${ }^{6}$ Marvel and McCafferty (1984) show that a manufacturer may use retailers as certifiers for their qualities without investigating the quality signal.

${ }^{7}$ By choosing for instance to sell its product only through luxury stores, a firm actually restricts its sales to the richest consumers who shop in these stores.

${ }^{8}$ Lexus is not distributed by usual Toyota car dealers.

${ }^{9} \mathrm{http}: / /$ fr.slideshare.net/thecaptain777/lexus-case-emotional-price

${ }^{10} \mathrm{http}: / /$ articles.chicagotribune.com/2013-03-13/business/chi-amazon-cuts-price-of-kindle-fire-20130313_1_kindle-fire-tablet-amazon-s-kindle-chad-bartley
} 
AmTran Technology, which handles production. ${ }^{11}$ Of course, to confirm that Amazon and Vizio cases fit the strategy described, we would need to see them raise their prices in the future as Lexus has done.

\section{Related literature}

Our article is related to two strands of signalling literature in which the monopolist signals high quality by directly or indirectly manipulating its output level through rationing (queuing, limited editions, etc.) or non-dissipative advertising. In these two strands of literature, the high quality firm's sales level is lower than that of the low quality firm and its price higher. This follows from the (first-period) 'profit margin effect' already described: restricting sales makes mimicry more costly to a low quality firm since it has, when mimicking, a higher (firstperiod) profit margin.

In our two-period model, there is in addition a second-period 'sales constraint' effect, absent from all the literature: the first-period output decision constrains the second-period sales. When the cost/ quality ratio is increasing (resp. decreasing), i.e. higher (resp. lower) for $\mathrm{H}$ than for $\mathrm{L}$, this effect goes into the same (resp. opposite) direction as (resp. to) the 'profit margin effect' since L is more (resp. less) constrained in the second period than $\mathrm{H}$. When the cost/quality ratio is strongly decreasing, the sales constraint effect becomes stronger and $\mathrm{H}$ has higher sales and lower price than $\mathrm{L}$ in our model equilibrium.

\section{Rationing as a signal of product quality}

Several papers focus on the importance of rationing quantity and creating shortages as a signal of high product quality, whether this is done or not in combination with price and/or advertising signalling (Franklin and Faulhaber 1990; Bandyopadhyay, Dongy, and Qinz 2010; Kim 2002; Stock and Balachander 2005). There is some concordance between our results and those of rationing literature.
In Bandyopadhyay, Dongy, and Qinz (2010), for instance, rationing makes mimicry more costly for a low quality firm since it has, when mimicking, a higher profit margin. ${ }^{12}$ A somewhat similar mechanism is at play in our article in the 'targeting elites' case, in which a high quality firm signals its quality by a level of supply lower than the low quality firm's one and a higher price.

However, besides the existence in our model of the 'sales constraint effect', a difference with our approach is that, in the aforementioned models, rationing is random, ${ }^{13}$ whereas in ours only the less valuable customers may be rationed, virtually or actually, so that rationing is efficient.

\section{Non-dissipative ${ }^{14}$ advertising as a signal of unobservable product quality}

There are several papers that consider non-dissipative informative and/or persuasive advertising, which affects demand directly and then output indirectly. Most of them (Zhao 2000; Orzach, Overgaard, and Tauman 2002; Bagwell and Overgaard, 2005) conclude that the high quality firm signals quality by advertising less than the low quality one because the low quality firm, which has a strong incentive to advertise when mimicking, is thus deterred from mimicry. ${ }^{15}$ A first difference is that these papers consider random advertising, which identically affects the demand of all consumers whatever their type, whereas our approach is more similar to targeted advertising which plays on the frontier between (fully) informed and non-informed consumers. A second difference is that we obtain the equivalent of their 'modest advertising' result for a given subset of parameter values but that the opposite result (say 'over-advertising') holds for another subset.

\section{Main results}

We check the existence of a perfect Bayesian equilibrium in a two-period model, where a firm produces

\footnotetext{
${ }^{11} \mathrm{http} / / /$ www.studymode.com/essays/Best-Cost-Strategy-Vs-Low-Low-Cost-Strategy-621901.html

${ }^{12}$ Stock and Balachander's (2005) model is different since they consider two types of audiences: informed and uninformed consumers, and assume a zero or small cost differential, thus eliminating the 'price margin effect'. Signalling quality to the uninformed consumers is possible through the scarcity of the product or the price. Scarcity may signal quality because it hurts more the low quality firm targeting uninformed consumers.

${ }^{13}$ The probability of obtaining the good is uniform over consumers' types.

${ }^{14}$ There is a substantial literature (see Nelson 1974; Milgrom and Roberts 1986; for the pioneering papers), dealing with what is commonly known as dissipative advertising, which amounts to 'burning' money in order to signal high quality.

${ }^{15}$ Notice that Gonzalez (2000) reaches a different conclusion since in his model, though advertising may be used to inform customers, only price signals quality.
} 
a good, whose quality (low or high) is not initially observable to consumers but which they come to learn in the second period. The firm might signal its quality by price and by targeting a given fraction of the consumers that have the highest preferences for quality. In the case where the firm chooses not to serve all would-be consumers, this is done by choosing an appropriate distribution network (mass merchandisers versus luxury shops, for instance). We show that in such a situation, the optimal choice of the firm depends on the quality ratio ${ }^{16}$ and/or the cost ratio. ${ }^{17}$

We first analyse two benchmark cases: the fullinformation equilibrium, which is shown to be a separating equilibrium when the gain in quality is paid for by a much higher unit cost of production, and the one-period case where we prove that pure price signalling is always optimal. We then analyse how quality is signalled, i.e. characterize the set of separating equilibria, which amounts to comparing the first-period (price, output) pairs of the two firms when they are correctly recognized by customers. It turns out that, depending on parameter values, a high quality firm can signal its quality either by a level of supply lower than the low quality firm's one and a higher price ${ }^{18}$ (the 'targeting elites' case) or, on the contrary, by a higher supply and a lower price ${ }^{19}$ (the 'mass selling' case). The former is the case when, at a given price, producing a higher quality good increases the demand for the good less or slightly more than its cost, ${ }^{20}$ while the latter when producing a higher quality increases the demand for the good much more that its cost. ${ }^{21}$ We then study the way quality is optimally signalled, i.e. in the set of separating equilibria, we focus on the least cost separating equilibria (LCSE), the only ones to satisfy Cho and Kreps' (1987) intuitive criterion. We show that there exists almost everywhere a unique LCSE. We contrast two different strategies: pure price signalling and signalling by a low price and selective distribution. We prove that the former is the more beneficial when producing high quality goods is relatively more costly, the latter when this is relatively cheaper.
The remainder of the article is organized as follows. Section II introduces the model, briefly presents the outcome of the second period and defines the separating and the least cost equilibria. Section III characterizes, on the one hand, the benchmark full-information equilibrium and gives conditions under which it is a separating equilibrium. On the other hand, it considers the one-period case, showing that it is never optimal to restrict consumers' access to the good otherwise than by price. Section IV provides a detailed analysis of the equilibrium of the market with asymmetric information (LCSE), giving conditions for pure price signalling on the one hand, selective distribution on the other and comparing equilibrium (first-period) output and price with their full-information values. Finally, Section V concludes the article. All proofs are relegated to the Appendix.

\section{The model}

We consider a monopolistic producer who has just developed a new product. The quality of the product may be high $\left(q_{H}\right)$ or low $\left(q_{L}\right)$. The firm knows the true quality of its product but the potential consumers do not. Their common prior is such that the product is a high quality one with probability $\mu$ and a low quality one with probability $(1-\mu)$. This probability is common knowledge. There is no direct way by which the firm could inform the consumers of the true quality of its product before they first purchase it.

The consumers are distributed uniformly on $[0,1]$ according to their marginal utility of quality $\theta$ in the two periods. In a given period, a type $\theta$-consumer derives a utility

$U=\left\{\begin{array}{ll}\theta q_{X}-P_{X} & \text { if he buys one unit of the good } X(X=H, L) \\ 0 & \text { if he stays out of the market }\end{array}\right.$,

$q_{X}$ and $P_{X}$ being, respectively, the quality and the price of the good of quality $X$. The full-information demand for good $X$ is accordingly equal to $1-\frac{P_{X}}{q_{X}}$.

\footnotetext{
${ }^{16}$ The quality ratio is the ratio between high and low product qualities.

${ }^{17}$ The cost ratio is the ratio between the high quality firm's cost and the low quality firm's cost.

${ }^{18}$ Notice that this does not necessarily imply equilibrium 'rationing': a high price may simply reduce demand and accordingly sales.

${ }^{19}$ Notice that this is consistent at equilibrium with selective distribution.

${ }^{20}$ Precisely the unit cost of quality is increasing or slightly decreasing.

${ }^{21}$ Precisely the unit cost of quality is steeply decreasing.
} 
Since one consumer buys at most one unit of the good, $c_{X}(X=H, L)$ is the cost which the firm has to bear in order to manufacture and deliver one unit of the good of quality $X$ to one (more) consumer. Producing a high quality product is assumed to be more costly than manufacturing a low quality one so that $c_{L} \leq c_{H}$.

The following assumption will be useful to ensure the existence of non-trivial equilibria since it states that the utility derived by the highest consumers' type from consuming one unit of the good of quality $X$ is higher than the unit cost of production of that good.

\section{Assumption 1:}

$$
q_{X}>c_{X} \Leftrightarrow b_{X}<1, X=H, L .
$$

This ensures that the highest type may derive some positive utility from consuming the good.

In the following, we shall denote $b_{X}=\frac{c_{X}}{q_{X}}$ (with $X=L, H)$ the cost/quality ratio of the quality $X$ product, $k=\frac{q_{H}}{q_{L}}>1$ the quality ratio and $\lambda=$ $\frac{c_{H}}{c_{L}}>1$ the cost ratio.

In the case of increasing (resp. decreasing) cost of quality, we shall observe that $b_{L} \leq b_{H}$ (resp. $b_{H} \leq$ ) or, equivalently, that $\lambda \geq k$ (resp. $\lambda \leq k$ ). Note that $\lambda / k=b_{H} / b_{L}$ so that, the higher this ratio is, the more the cost quality ratio will be increasing.

Assuming, similarly to Milgrom and Roberts (1986), that quality is not a choice variable but exogenously given, we consider the following twoperiod distribution and pricing game.

(1) In the first period, nature selects quality, the firm observes it and decides simultaneously on its price $P_{1}$ and the subset $\left[\theta^{*}, 1\right]$ of consumers who will buy the good. For customers' beliefs $p\left(P_{1}, \theta^{*}\right)$, the expected quality is

$$
q^{e}=p\left(P_{1}, \theta^{*}\right) q_{H}+\left(1-p\left(P_{1}, \theta^{*}\right)\right) q_{L} .
$$

In order for all customers in $\left[\theta^{*}, 1\right]$ to be willing to buy, the firm has to set a price $P_{1} \leq \theta^{*} q^{e}$ such that they derive a positive utility from buying. When
$P_{1}=\theta^{*} q^{e}$, all consumers who derive a positive utility from consuming the good do buy. There is no need for an exclusive distribution network. Setting the price at this level is sufficient. When $P_{1}<\theta^{*} q^{e}$, consumers in $\left[\frac{P_{1}}{q^{e}}, \theta^{*}\right)$ would want to buy were the firm willing to inform and supply them. In that case, an exclusive distribution network is needed to ensure that only customers $\left[\theta^{*}, 1\right]$ will buy.

What this assumption introduces is the strategic ability for a high quality firm to signal the quality of its product by making the good available only to consumers with a greater willingness to pay, even when some other consumers, if informed of the existence of the product, would be willing to buy it at the posted price. This is equivalent to an efficient rationing of the potential demand. These customers, ${ }^{22}$ after observing $P_{1}$ and $\theta^{*}$, revise their beliefs about the quality of the good, represented by the probability $p\left(P_{1}, \theta^{*}\right)$ that the good is a high quality one, and make their initial purchase decisions.

(2) In the second period, all consumers know, either from direct use or word-of-mouth communication, whether the good is a high or low quality one. But widening the distribution network and/or supplying higher quantities to existing retailers takes time, and/or demand itself is 'viscous', so that second-period sales, $Q_{2}$, are assumed to be constrained by first-period ones, ${ }^{23} Q_{1}$. Firm $X$ 's problem is simply to select its price $P_{2}$ in order to maximize its profit ${ }^{24}\left(1-\frac{P_{2}}{q_{X}}\right)\left(P_{2}-c_{X}\right)$ subject to the capacity constraint $\left(1-\frac{P_{2}}{q_{X}}\right) \leq Q_{1}$. Since the second-period sales are by assumption limited by the first-period ones, there is no incentive for the firm to choose initially an oversized distribution network, ${ }^{25}$ so that, without loss of generality, $Q_{1}=1-\theta^{*}$.

The second-period equilibrium is then straightforwardly obtained as

\footnotetext{
${ }^{22}$ We assume that the informed buyers may observe how many they are, because they see that only some specific outlets distribute the good.

${ }^{23} \mathrm{~A}$ milder assumption would leave our qualitative results unchanged.

${ }^{24}$ Note that $\frac{P 2}{Q X}$ is the marginal consumer indifferent between buying product $\mathrm{X}$ or not buying at all.

${ }^{25}$ Actually, it is quite easy to show that a high quality firm has, under incomplete information, an incentive to choose the smallest possible distribution network to achieve its intended sales level when this may dissuade mimicking.
} 


$$
P_{2}^{*}=\max \left\{\theta^{*} q_{X}, \frac{q_{X}\left(1+b_{X}\right)}{2}\right\}
$$

and

$$
\pi_{2}^{X}\left(\theta^{*}\right)=\left\{\begin{array}{lll}
q_{X} \frac{\left(1-b_{X}\right)^{2}}{4} & \text { if } \quad \theta^{*} \leq \frac{\left(1+b_{X}\right)}{2} \\
q_{X}\left(1-\theta^{*}\right)\left(\theta^{*}-b_{X}\right) & \text { if } \quad \theta^{*} \geq \frac{\left(1+b_{X}\right)}{2}
\end{array}\right.
$$

Finally, we assume that the firm discounts second-period profits by factor $\beta$ and denote

$$
\Pi\left(P_{1}, \theta^{*}, X, p\right)
$$

the function giving the expected present value of a firm's profit of true quality $X$ that sets an introductory price $P_{1}$, sells to consumer types higher than $\theta^{*}$ and is believed with probability $p\left(P_{1}, \theta^{*}\right)$ to be of quality $H$. More precisely,

- For a given couple $\left(P_{1}, \theta^{*}\right)$ such that $P_{1} \leq \theta^{*} q_{H}$, the profit of the high quality firm when $p\left(P_{1}, \theta^{*}\right)=1$, i.e. when it is recognized as such, is given by

$$
\begin{aligned}
\Pi\left(P_{1}, \theta^{*}, H, 1\right)= & \left(1-\theta^{*}\right)\left(P_{1}-b_{H} q_{H}\right) \\
& +\beta \pi_{2}^{H}\left(\theta^{*}\right),
\end{aligned}
$$

where $\pi_{2}^{H}\left(\theta^{*}\right)$, according to Equation (3), takes two different values according to whether $H$ is or is not capacity constrained in the second period. Note that the isoprofits curves in the $\left(\theta^{*}, P_{1}\right)$ - space are always strictly convex.

- The profit of the low quality firm when $p\left(P_{1}, \theta^{*}\right)=0$, i.e. when it is recognized as such, is simply its full-information strategy one, i.e.

$$
\begin{gathered}
\Pi\left(\frac{q_{L}\left(1+b_{L}\right)}{2}, \frac{1+b_{L}}{2}, L, 0\right) \\
=(1+\beta) q_{L} \frac{\left(1-b_{L}\right)^{2}}{4} .
\end{gathered}
$$

Since its optimal output level is the same in both periods, it is never capacity constrained in the second period.

- The profit of the low quality firm, when it is mistaken for a high quality one, is

$$
\begin{aligned}
\Pi\left(P_{1}, \theta^{*}, L, 1\right)= & \left(1-\theta^{*}\right)\left(P_{1}-b_{L} q_{L}\right) \\
& +\beta \pi_{2}^{L}\left(\theta^{*}\right)
\end{aligned}
$$

where $\pi_{2}^{L}\left(\theta^{*}\right)$, according to Equation (3), takes two different values according as $L$ is or not capacity constrained in the second period. Once again, the isoprofits curves in the $\left(\theta^{*}, P_{1}\right)$ - space are always strictly convex.

- Finally, when the high quality firm chooses a price-quantity couple different from $H$ 's equilibrium one, the equilibrium beliefs imply that it is taken for a low quality one. Given that it never benefits from selecting a first-period price strictly lower than $\theta^{*} q_{L}$, its profits can be expressed as a function of $\theta^{*}$ alone:

$$
\begin{aligned}
\Pi\left(\theta^{*} q_{L}, \theta^{*}, H, 0\right)= & \left(1-\theta^{*}\right)\left(\theta^{*} q_{L}-b_{H} q_{H}\right) \\
& +\beta \pi_{2}^{H}\left(\theta^{*}\right) .
\end{aligned}
$$

It is readily shown that these profits are maximum $^{26}$ at $\theta_{H L}=\frac{1}{2}+\frac{(1+\beta) \lambda b_{L}}{2(1+k \beta)}>\theta_{H}, \quad$ yielding profits:

$\max _{\theta^{*}} \Pi\left(\theta^{*} q_{L}, \theta^{*}, H, 0\right)=q_{L} \frac{\left(1+k \beta-(1+\beta) \lambda b_{L}\right)^{2}}{4(1+k \beta)}$.

Let us define $\bar{\lambda}=\frac{1+k \beta}{1+\beta}$ and remark that $\theta_{H L}>(<) \theta_{L}$ iff $\lambda>(<) \bar{\lambda}$.

We shall focus in the following on separating equilibria, at which the high quality firm signals its quality by choosing a strategy $\left(P_{1}, \theta^{*}\right)$ such that the low quality firm prefers to reveal its true quality rather than to mimic the high quality firm. At the same time, $\left(P_{1}, \theta^{*}\right)$ must be such that the high quality firm is better off signalling its true quality than being perceived as a low quality one. In a separating equilibrium, the two types of sellers choose different prices and outputs. Therefore, the initially uninformed consumers, after observing the first-period sales and price levels, infer the true quality of the product. More precisely,

Definition 1: A sequential separating equilibrium is a pair $\left(P_{1}, \theta^{*}\right) \neq\left(P_{L}, \theta_{L}\right)$ such that the incentive constraints

\footnotetext{
${ }^{26}$ Note that $\Pi\left(\theta^{*} q_{L}, \theta^{*}, H, 0\right)$ is continuously differentiable with respect to $\theta^{*}$ at $\theta^{*}=\theta_{H}$ and that it is in addition strictly concave. Since $\theta_{H L}>\theta_{L}$ it then corresponds to the unique maximum of $\Pi\left(\theta^{*} q_{L}, \theta^{*}, H, 0\right)$.
} 


$$
\Pi\left(P_{1}, \theta^{*}, H, 1\right) \geq \max _{\theta^{*}} \Pi\left(\theta^{*} q_{L}, \theta^{*}, H, 0\right),
$$

and

$$
\begin{aligned}
& \max _{\theta^{*}} \Pi\left(\frac{q_{L}\left(1+b_{L}\right)}{2}, \frac{1+b_{L}}{2}, L, 0\right) \\
& \quad \geq \Pi\left(P_{1}, \theta^{*}, L, 1\right),
\end{aligned}
$$

are satisfied, as well as the participation constraint

$$
P_{1} \leq \theta^{*} q_{H}
$$

Customers' beliefs are given by

and $^{27}$

$$
p\left(P_{1}, \theta^{*}\right)=1
$$

$$
p(P, \theta)=0, \forall(P, \theta) \neq\left(P_{1}, \theta^{*}\right) .
$$

We shall denote $S$ the set of separating equilibria.

Condition IC1 means that the profit of a high quality firm is higher, when it is recognized as such, than the maximum profit it can obtain when it is mistaken for a low quality one. ${ }^{28}$ Condition IC2 implies that a low quality firm has no incentive to mimic a high quality one. The condition $P C$ guarantees that all initial customers of types $\theta \geq \theta^{*}$ are indeed willing to buy the high quality good at price $P_{1}$. When these constraints are satisfied, consumers rationally infer that the firm sending out a signal is the high quality provider: the pair $\left(P_{1}, \theta^{*}\right)$ is a separating equilibrium.

In the set of separating equilibria, it is natural to focus on the separating equilibrium which gives to the high quality firm the largest profits, namely the 'LCSE'.

Definition 2: A least-cost separating equilibrium (LCSE) is a couple $\left(\bar{P}_{1}, \bar{\theta}^{*}\right) \neq\left(P_{L}, \theta_{L}\right)$ maximizing $\Pi\left(P_{1}, \theta^{*}, H, 1\right)$ subject to the incentive constraints $I C 1$ and $I C 2$ and the participation constraint $P C$.

The LCSE is more precisely a profit-maximizing separating equilibrium. Accordingly, an LCSE exists as long as the set $S$ of separating equilibria is not empty, i.e. when $\lambda \neq \bar{\lambda}$.
The LCSE clearly satisfies the Cho-Kreps' intuitive criterion (Cho and Kreps 1987) which requires that there should be no feasible deviation from it, yielding higher profits to the high quality firm, when recognized as such, while giving lower profits to the low quality firm, though mistaken for a high quality one. $^{29}$ Since, the LCSE maximizes $H$ 's profits under the two constraints $I C 2$ and $P C$, any couple giving higher profits to $H$ than the LCSE necessarily violates either (a) the participation constraint, and is accordingly not feasible, or (b) the incentive constraint, and hence gives higher profits to $L$ (when mistaken for $H$ ) than the LCSE and is therefore not a separating equilibrium.

\section{Some benchmarks}

In this section, we consider some important benchmark cases. First, we derive the full-information equilibrium and the condition under which it is a separating equilibrium and hence an LCSE. This condition means that the cost of quality is strongly increasing, i.e. the cost per unit of quality is substantially higher for a high quality product.

The second benchmark is the one-period case where signalling is by price alone (no equilibrium rationing).

\section{The full-information equilibrium}

Consider the full-information case, in which consumers know with certainty whether the good is a high or low quality one. The profits in period $t$ $(t=1,2)^{30}$ of a firm of quality $X$ are obtained as

$$
\pi_{X_{t}}=\left(P_{X_{t}}-c_{X}\right)\left(1-\frac{P_{X_{t}}}{q_{X}}\right)
$$

so that we obtain the same equilibrium in both periods, which is such that ${ }^{31}$

$$
Q_{X_{t}}^{*}=\frac{1}{2}-\frac{b_{X}}{2}, t=1,2
$$

and

\footnotetext{
${ }^{27}$ As put by Milgrom and Roberts $(1986,104), p(P, \theta)$ has simply to be 'sufficiently small (e.g. zero) that neither player wishes to deviate to $p(P, \theta)$ '.

${ }^{28}$ Which happens, according to the definition of beliefs, when it chooses a pair different from $\left(P_{1}, \theta^{*}\right)$.

${ }^{29}$ This is always the case that occurs if, when deviating, the low quality firm is (mis)taken with probability 1 being a high quality one.

${ }^{30}$ Under full information, the second-period sales are no constrained by the level of first-period ones.

${ }^{31}$ We assumed that $b_{X}<1, X=H, L$, so that both the low and the high quality firm have a positive demand under full information.
} 


$$
P_{X_{t}}^{*}=P_{X}=\frac{q_{X}\left(1+b_{X}\right)}{2}=\frac{q_{X}+c_{X}}{2}
$$

It is interesting to determine when the complete information pair is a separating equilibrium (in which case it is also an LCSE). This is done in Proposition 1 as follows:

Proposition 1: The complete information pair $\left(P_{1}, \theta^{*}\right)=\left(P_{H}, \theta_{H}\right)$ is a (least cost) separating equilibrium iff

$$
\lambda \geq \hat{\lambda}
$$

with $\hat{\lambda}=k \frac{b_{L}+\sqrt{(k-1)\left(k+\beta-b_{L}^{2}-\beta b_{L}^{2}\right)}+\beta b_{L}}{b_{L}(k+\beta)}>k$.

Proposition 1 shows that the complete information pair is a separating equilibrium when the cost of quality increases strongly, ${ }^{32}$ i.e. the ratio $\lambda=c_{H} / c_{L}$ between the unit costs is large relative to the quality ratio $k=q_{H} / q_{L}$. Indeed, the low quality firm faces two contradictory strategic effects when mimicking the high quality firm. The first positive effect is the benefit from a first-period higher price which is all the higher in so far as the quality ratio is higher. ${ }^{33}$ The second negative effect is the cost from being constrained in its sales level in both periods. This negative effect is all the stronger in so far as the differential between full-information market shares is higher, i.e. the higher is the unit quality costs differential, since the difference between the fullinformation equilibrium market shares is equal to $b_{H}-b_{L} / 2$. As a result, the low quality firm chooses to signal its true type.

\section{The one-period case: optimal signalling is by price alone}

In order to better understand under what circumstances a high quality firm may find it worthwhile to signal quality by not serving some would-be customers, it is interesting to see what happens when the model degenerates to a one-period one. Formally, we obtain the one-period case from our model by simply setting $\beta=0$, so that results for this specific case follow from the more general propositions that will be demonstrated in the following sections. The main qualitative result is that, in a one-period setting, at a (least cost) separating equilibrium, all consumers who derive a positive utility from the good can buy it: signalling is by price alone.

This is easily seen. Suppose that $\left(\frac{P_{1}}{q_{H}}, \theta^{*}\right)$ is nonvoid. The constraint (IC2) must then bind since otherwise the firm could increase its profits by raising its price, so that

$$
1-\theta^{*}=q_{L} \frac{\left(1-b_{L}\right)^{2}}{4\left(P_{1}-c_{L}\right)} .
$$

Now, substituting $1-\theta^{*}$ for its value from the above equation, the high quality firm's profit may be rewritten as

$$
\Pi\left(P_{1}, \theta^{*}, H, 1\right)=q_{L} \frac{\left(1-b_{L}\right)^{2}}{4} \frac{\left(P_{1}-c_{H}\right)}{\left(P_{1}-c_{L}\right)},
$$

Since $c_{H}>c_{L}$, this is an increasing function of $P_{1}$, so that Firm $\mathrm{H}$ would be able to increase its profits by raising its price.

\section{Perfect Bayesian equilibria in a two-period model}

In this section, we investigate the firm's distribution and pricing strategies in a situation of asymmetric information, where consumers observe the output level and the product's price but are uncertain about the firm's quality. Throughout, we employ the notion of perfect Bayesian equilibrium. As usual, this requires the monopolist's strategy to be sequentially rational and consumers' beliefs to conform with Bayes' rule whenever it applies.

We first start by more generally characterizing the separating equilibria, since this is important to understand how a high quality firm may differentiate itself from a low quality one and what the underlying effects that come into play are. Remark that, at this stage, the focus is only on the comparison between the first-period (price, output) pairs of the two firms. The possible use of selective distribution networks will be investigated later.

We then focus on the LCSE in order to understand under what circumstances, contrary to what happens in a one-period setting, the high quality

\footnotetext{
${ }^{32}$ We easily show that the total revenues of the high quality firm are, in the case of a decreasing marginal cost of quality, unambiguously greater than those of the low quality one, so that the complete information pair is never a separating equilibrium under this condition.

${ }^{33}$ The price differential equals $\frac{q_{H}\left(1+b_{H}\right)}{2}-\frac{q_{L}\left(1+b_{L}\right)}{2}=\frac{1}{2} q_{L}\left(k\left(1+b_{H}\right)-1-b_{L}\right)$.
} 
firm may find it profitable not to serve all consumers who would derive a positive surplus from buying.

It will be important, for both purposes, to identify precisely, when the incentive constraint (IC2) is binding, what the effects on the high quality firm's profits of a restriction of first-period sales are . Substituting in Equation (4), for $P_{1}$ its value from (IC2), one obtains in that case

$$
\begin{aligned}
\Pi\left(P_{1}, \theta^{*}, H, 1\right)= & \left(1-\theta^{*}\right)\left(c_{L}-c_{H}\right) \\
& +\beta\left(\pi_{2}^{H}\left(\theta^{*}\right)-\pi_{2}^{L}\left(\theta^{*}\right)\right) .
\end{aligned}
$$

Then, differentiating with respect to $\theta^{*}$ in order to determine the effect on profits of a restriction of sales, one obtains

$$
\begin{aligned}
\frac{\partial \Pi\left(P_{1}, \theta^{*}, H, 1\right)}{\partial \theta^{*}}= & \left(c_{H}-c_{L}\right) \\
& +\beta \frac{\partial\left(\pi_{2}^{\mathbf{H}}\left(\theta^{*}\right)-\pi_{2}^{\mathbf{L}}\left(\theta^{*}\right)\right)}{\partial \theta^{*}} .
\end{aligned}
$$

The first term in the RHS corresponds to the (always) positive profit margin effect as in the one-period case. But there is now a second term which corresponds to what we already called the 'sales constraint effect', which is the differential effect on H's and mimicking L's second-period profits from a restriction of sales. When neither $\mathrm{H}$ nor $\mathrm{L}$ is second-period constrained, ${ }^{34}$ this effect is positive: restricting sales has more effect on $\mathrm{L}$ and then allows $P_{1}$ to be increased without inducing $\mathrm{L}$ to mimic. If only $\mathrm{H}$ is second-period constrained, ${ }^{35}$ this effect is directly negative: restricting sales has no effect on $L$ but a negative one on $\mathrm{H}$. When both firms are second-period constrained, the answer has to be qualified, since the second-period profits differential is not linear (but concave) in sales level.

\section{How is quality signalled? Targeting elites versus mass selling}

Lemma 1 characterizes the set of separating equilibria where the high quality firm chooses a different market share and price strategies relative to the low quality one in order to signal its product quality. This Lemma shows that high quality is to be signalled in two opposite ways depending on the underlying cost structure. When H's cost/quality ratio is greater or even not substantially lower than L's, signalling requires a lower output and a higher price. When it is much lower, signalling is by a higher output and a lower price.

Lemma 1: The set of separating equilibria is nonempty iff $\lambda \neq \bar{\lambda}$. At a separating equilibrium:

- whenever the cost of quality is increasing or slightly decreasing, i.e. $\lambda>\bar{\lambda}$ (CASEA: Targeting Elites), the high quality firm signals quality by a smaller market-share than the low quality full-information one, i.e. $\theta^{*}>\theta_{L}$ and by a higher price, i.e. $P_{1}>P_{L}$

- whenever the cost of quality is steeply decreasing, i.e. $\lambda<\bar{\lambda}$ (CASE B: Mass selling), the high quality firm signals quality by a higher market share than the low quality full-information one, i.e. $\theta^{*}<\theta_{L}$ and by a smaller price, i.e. $P_{1}<P_{L}$.

Lemma 1 allows two rather different cases to be distinguished. Note that there is no separating equilibrium when $\lambda=\bar{\lambda}$. In that case, $\left(P_{L}, \theta_{L}\right)$ is the only pair that satisfies the incentive and participation constraints but choosing this pair does not allow a high quality firm to differentiate itself from a low quality one: it is impossible to signal high quality.

When the cost of quality is either increasing or only slightly decreasing, i.e. $\lambda>\bar{\lambda}$ (CASE A), at any separating equilibrium, the high quality firm signals its quality by choosing a market share smaller than the full-information market share of the low quality firm (i.e. by increasing $\theta^{*}$ and targeting only consumers with higher preferences for quality) and a higher first-period price without inducing the low quality firm to mimic it. This is what we call the 'targeting elites' case.

Indeed, a smaller market share (a higher $\theta^{*}$ ) signals a high quality firm, since a low quality firm, when it mimics a high quality one, suffers more than the latter from a market reduction which, accordingly, dissuades mimicry.

\footnotetext{
${ }^{34}$ Notice that this may happen iff the cost of quality is increasing

${ }^{35}$ Notice that this may happen iff the cost of quality is decreasing.
} 
When the cost of quality is steeply decreasing, i.e. $\lambda<\bar{\lambda}$ (CASE B), at any separating equilibrium, the high quality firm signals quality by choosing a market share higher than the full-information market share of the low quality firm and a first-period price which is lower (according to Lemma 2 in the Appendix). This is what we call the 'mass selling' case.

The intuition underlying these contrasted results lies in our two-period framework. In the first period, the low quality firm mimicking the high quality one has a higher profit margin since it has a lower cost. So it benefits more than the high quality firm from market expansion. This is the 'profit-margin effect' which, in various disguises, is well-known in the literature. It corresponds to the first term in the RHS of Equation (12). Reducing the sales level is a way to deter mimicry and thus to be able to raise the price and increase H's profits. In the second period, a 'sales constraint effect' is at work, which corresponds to the second term in the RHS of Equation (12).

In the case of increasing cost of quality, the high quality firm $\mathrm{H}$, which has a lower full-information output than the low quality one $\mathrm{L}\left(1-\theta_{H}<1-\theta_{L}\right)$, is unconstrained, when its first-period output is equal to L's, while the low quality firm $\mathrm{L}$ when mimicking is unconstrained (resp. constrained) for a first-period output level higher (resp. lower) than its full-information equilibrium sales. This reinforces the first period, profit-margin effect or, at least, does not contradict it. Both effects of a sales restriction being positive, Case A obtains: for any sales level higher than L's full-equilibrium one, $1-\theta_{L}, \mathrm{H}$ then achieves lower profits than at $\left(P_{L}, 1-\theta_{L}\right)$ and has accordingly an incentive to deviate (IC1 is trivially violated). Accordingly, all separating equilibria must have a lower output (and a higher price) than L's full-information equilibrium ones.

In the case of decreasing cost of quality, on the contrary, it is the high quality firm that is more constrained in the second period than the mimicking low quality one. Here, the first-period 'profit margin' and second-period 'sales constraint' effects work in opposite directions. The sales constraint effect, evaluated at $\theta_{L}$ (which is here $>\theta_{H}$ ), is indeed obtained $^{36}$ as

$$
\beta \frac{\partial\left(\pi_{\mathbf{2}}^{\mathbf{H}}\left(\theta_{L}\right)-\pi_{\mathbf{2}}^{\mathbf{L}}\left(\theta_{L}\right)\right)}{\partial \theta^{*}}=\beta q_{H}\left(b_{H}-b_{L}\right)<0,
$$

and clearly negative. Which effect dominates depends on parameter values. When the secondperiod effect remains smaller in absolute value, i.e. when $\left(c_{H}-c_{L}\right)+\beta q_{H}\left(b_{H}-b_{L}\right)>0$, or, equivalently, $\lambda>\bar{\lambda}$, choosing a first-period market share smaller than the low quality firm's full-information output, and a higher first-period price, is the appropriate way to deter mimicry, namely Case A continues to hold. When the second-period effect becomes higher, i.e. when $\lambda<\bar{\lambda}$, choosing a firstperiod market share higher than the low quality firm's full-information output, and a lower first-period price, becomes the appropriate way to deter mimicry, that is Case B obtains. Indeed, for any sales level higher than L's full equilibrium one, $\mathrm{H}$ then obtains lower profits than at $\left(P_{L}, 1-\theta_{L}\right)$ and has accordingly an incentive to deviate (IC1 is trivially violated). Accordingly, all separating equilibria must have a higher output (and a lower price) than L's full-information equilibrium ones. Of course, when $\lambda=\bar{\lambda}$, the two effects cancel out exactly so that $\mathrm{H}$ cannot signal its quality.

In Case $\mathrm{B}$, the high quality firm benefits more than the low quality one which mimics it, thanks to a market expansion. This is because, contrary to $\mathrm{L}, \mathrm{H}$ is constrained in its second-period sales. This 'capacity constraint' is here strong enough to dominate the first-period 'profit margin effect' which works in the opposite direction.

It should finally be noticed that, in order to characterize separating equilibria, the relevant comparison is between H's first-period price and market share $\left(P_{1}, 1-\theta^{*}\right)$ and L's. It is difficult at this stage to draw conclusions on the comparison with $\mathrm{H}$ 's full-information equilibrium values $\left(P_{H}, 1-\theta_{H}\right)$, essentially because that means comparing a set with a point.

\section{How is quality optimally signalled? Pure price signalling versus low price cum selective distribution}

As already stated, an LCSE is a profit-maximizing separating equilibrium. Accordingly, there exists an

\footnotetext{
${ }^{36}$ The left and right derivatives are identical.
} 


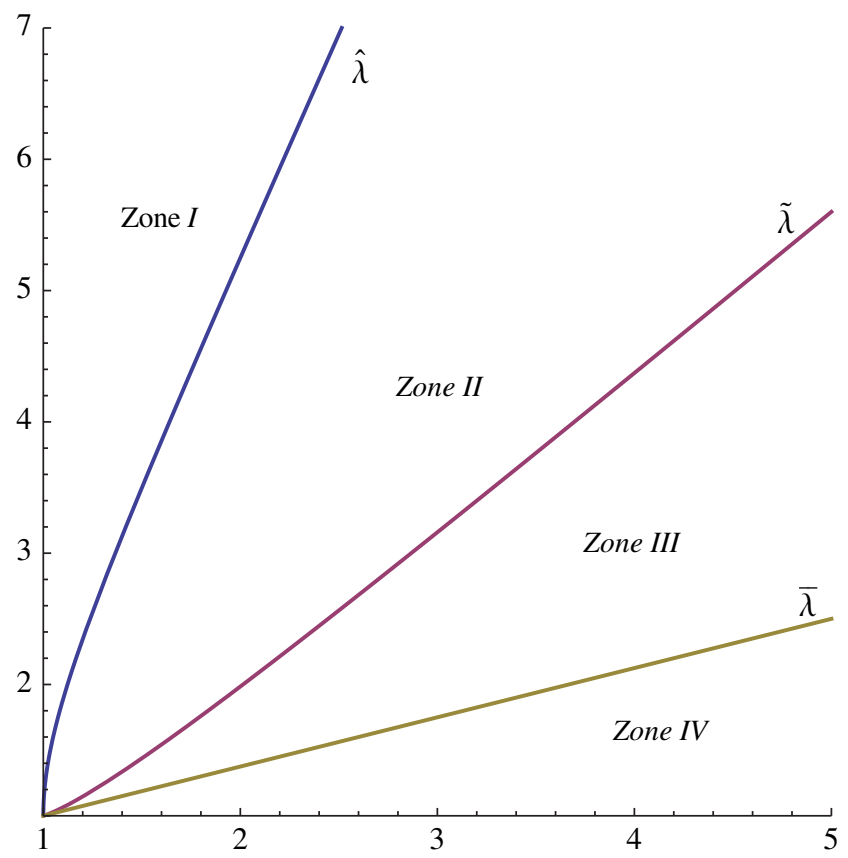

Figure 1. Regioning of LCSE in the $(k, \lambda)$ space for $\beta=0.6$ and $b_{L}=0.3$.

LCSE as long as there exists a separating equilibrium, i.e. iff $\lambda \neq \bar{\lambda}$. In this section, we characterize the LCSE of the game, focusing on the circumstances under which it is optimal for $\mathrm{H}$ to signal by price alone, serving every would-be consumer, and the ones when it is better not to serve all consumers who would derive a positive surplus from buying at the posted price.

Figure 1 depicts the zones of the four possible types of LCSE depending on the quality ratio and cost ratio. ${ }^{37}$ The LCSE in Zones I-III are separating equilibria corresponding to Case A of Lemma 1: the price (quantity) is higher (lower) than the corresponding one for a low quality firm. The LCSE in Zone IV corresponds to Case B.

However, our purpose here is to distinguish the cases where signalling is by price alone and the cases where it is by price and the exclusion of would-be consumers (through an exclusive distribution network) and to understand why the latter case, while impossible in a one-period model, may occur in the two-period one. As will appear in the following, Zones I and II of Figure 1 correspond to parameter values for which Firm $\mathrm{H}$ optimally signals quality by price alone. This is when the high quality firm is extremely inefficient in producing quality (the cost per unit of quality of Firm $H$ is substantially greater than the cost per unit of quality of Firm $L$ ). Zones III and IV correspond, on the other hand, to parameter values for which it becomes optimal to signal quality not only by price but also by effectively limiting the access of the good to highest type consumers (some potential customers are not allowed to buy). This is when the high quality firm is mildly inefficient or more efficient in producing quality.

\section{Signalling by price alone}

Proposition 2: When $\lambda \geq \widetilde{\lambda}$, i.e. when the cost /quality ratio is steeply increasing with the quality of the product, there is always a least cost separating equilibrium where signalling is by price alone, i.e. all would-be consumers are served. This LCSE is such that:

(i) Iff $\lambda \geq \hat{\lambda}$ (Zone I), the price and output levels of the high quality firm in both periods are the fullinformation ones, $\left(\bar{P}_{1}, \bar{\theta}^{*}\right)=\left(P_{H}, \theta_{H}\right)$. $H$ is not constrained in its second-period sales.

(ii) Iff $\lambda \in \widetilde{\lambda}, \widehat{\lambda}]$ (Zone II), the price (resp. output) level is constant in both periods and above (resp. below) its full-information value in both periods, and $H$ is accordingly constrained in its secondperiod sales:

$$
\left(\bar{P}_{1}, \bar{\theta}^{*}\right)=\left(\hat{\theta} q_{H}, \hat{\theta}\right),
$$

where $\hat{\theta}=\frac{1}{2}\left(1+\frac{b_{L}(1+\beta)+\sqrt{(k-1)\left(k+\beta-b_{L}^{2}-\beta b_{L}^{2}\right)}}{k+\beta}\right) \geq \theta_{H}$.

Proposition 2 shows that when firm $H$ is extremely inefficient in producing quality, not only does it not need to use a limitation of its distribution channel to signal quality but it is also not better off using it. Signalling by price alone is optimal and sales are determined by demand in both periods. Using or not using a selective distribution channel is indifferent: all consumers who may be willing to buy are allowed to. More specifically, when the cost/quality ratio is steeply

${ }^{37}$ Defining $\tilde{\lambda}=\frac{k(1+\beta)^{2} b_{L}+\sqrt{\beta^{2}(k-1)^{3}\left(k+\beta-(1+\beta) b_{L}^{2}\right)}}{(1+\beta)(k+\beta) b_{L}}$, Claim 1 in Appendix shows that $\widehat{\lambda}>\tilde{\lambda}>\bar{\lambda}$. In the same Claim, it is shown that $\widetilde{\lambda} \rightarrow k$ as $k \rightarrow 1$ and that $\tilde{\lambda}<k$ at least for $k$ in a right neighbourhood of 1 . This is useful to understand what follows. 
increasing $^{38}$ (Zone I in Figure 1), the LCSE corresponds to the full-information equilibrium (price, output) pair. In this case, it is much more costly to produce a high quality product; thus, the full-information output of a high quality firm is so much lower than the full equilibrium output of a low quality firm that the latter is naturally deterred from mimicking the former. However, when the cost/quality ratio is less steeply increasing with the quality of the product (Zone II in Figure 1), a high quality firm has to raise its price above its full-information value in order to deter a low quality one from mimicking it. In both cases, the price and output levels are the same in both periods. In the Zone II case, Firm H, as well as Firm L when it has mimicked the former in the first period, would both ideally seek to increase their sales in the second period. However, $\mathrm{L}$ suffers more than $\mathrm{H}$ from the limitation of sales at their first-period level. Accordingly, signalling by price alone is not very costly to $\mathrm{H}$. Such a strategy will be more costly when $H$, becoming more efficient in producing quality, suffers more from sales limitation.

Remark that, in the LCSE analysed in Proposition 2 , the equilibrium price of the high quality firm is higher than the price of the low quality one and its sales lower (Figures 2 and 3), corresponding to Case A of Lemma 1, without implying any kind of effective or virtual rationing.

Remark 1: Note that $\widetilde{\lambda}$ and $\bar{\lambda}$ both tend toward 1 as $\beta$ tends toward 0 . Accordingly, Zones III and IV tend to vanish to the limit as our model tends toward a one-period model: there is no equilibrium

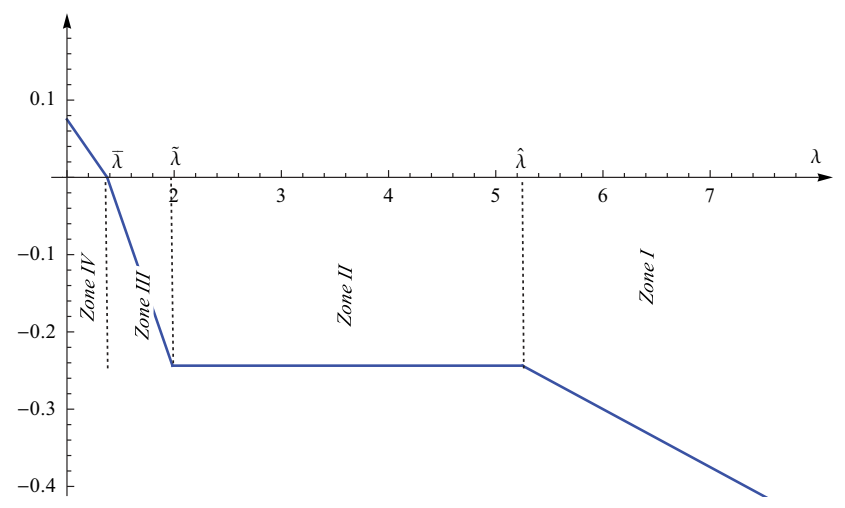

Figure 2. $\left(1-\bar{\theta}^{*}\right)-\left(1-\theta_{L}\right)$ w.r.t $\lambda$.

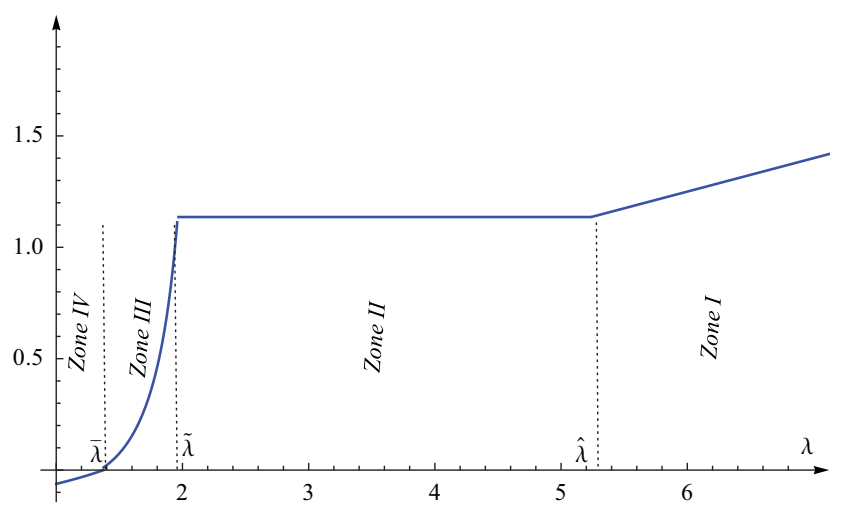

Figure 3. $\bar{P}_{1}-P_{L}$ w.r.t $\lambda$.

rationing in this case, where, in the limit, signalling is always done by price alone. This result is easy to generalize. In a one-period model, or a multiperiod model without viscosity of sales, it is never optimal to restrict supply below the demand level.

\section{Signalling by a low price cum selective distribution} In the case studied here, Firm $\mathrm{H}$ finds it profitable to sell more than it could under pure price signalling. It serves more customers at an initial low price and a higher second-period price: the first-period low price is a quality signal since only the high quality firm will be able to compensate the initial profits forgone, thanks to a higher second-period profit margin on a higher volume of sales, relative to the volume of sales when signalling is by price alone. Mimicking is in this way dissuaded. Initially denying access to the good to some consumers is a consequence of the strategy, since more consumers than targeted by the firm would want to buy the good at the initial low price while, in the second period, the higher price is enough to prevent them from buying.

Proposition 3: When $\lambda \in 1, \widetilde{\lambda}), \lambda \neq \bar{\lambda}$, i.e. when the cost /quality ratio is either mildly increasing or decreasing with the quality of the product, there is a least cost separating equilibrium where signalling is simultaneously by price and by an effective limitation of the distribution channel. This LCSE is such that (a) the output level of the high quality firm is constant in both periods and always lower than its full-information value ( $H$ is constrained in its second-period sales)

\footnotetext{
${ }^{38}$ That is when the cost ratio $\lambda$ is large enough with respect to the quality ratio $k$.
} 
and (b) the initial price $P_{1}$ is always lower than the second-period price, $P_{2}$. There are two subcases:

(i) When $\lambda \in(\bar{\lambda}, \widetilde{\lambda}]$ (Zone III), $\left(\bar{P}_{1}, \bar{\theta}^{*}\right)=\left(P_{A}, \theta_{A}\right)$ where $\theta_{A}=\frac{b_{L}(\beta+1)(\lambda-1)}{2 \beta(k-1)}+\frac{1}{2}>\theta_{H} \quad$ and $>\theta_{L}$, $P_{A}=\frac{q_{L}}{2} \frac{\left(b_{L}\left(\frac{(\lambda-1)}{(k-1)}\right)^{2}(\beta+1)^{2}-2 b_{L}^{2\left(\frac{(\lambda-1)}{L-1)}\right.}(\beta+1)^{2}+\beta\left(b_{L}^{2}+\beta b_{L}^{2}+1\right)\right.}{\beta-b_{L}\left(\frac{\lambda-1)}{(k-1)}(\beta+1)\right.}$.

(ii) When $\lambda \in 1, \bar{\lambda})$ (Zone IV), $\left(\bar{P}_{1}, \bar{\theta}^{*}\right)=\left(P_{B}, \theta_{B}\right)$, where $\theta_{H}<\theta_{B}=\frac{1}{2}+b_{L} \frac{\lambda(1+\beta)-1}{2 k \beta}<\theta_{L}, \quad P_{B}=$ $q_{L}\left(\frac{1}{2} \frac{k \beta\left(b_{L}-1\right)^{2}}{b_{L}+k \beta-\lambda b_{L}-\beta \lambda b_{L}}+b_{L}\right)$.

Notice that Assumption 1 (H.1) ensures that $\theta_{A}<1$ and $P_{A}>0$ and that $\lambda<\bar{\lambda}$ together with $b_{L}<1$ is enough to ensure that $\theta_{B}<1$ and $P_{B}>0$.

In the two subcases analysed in Proposition 3, ${ }^{39}$ Firm $H$ optimally signals its quality by price and by an effective limitation of its distribution channel to highest type consumers, equivalent to efficient rationing. In the second period, it raises its price to the maximum level such that all its first-period customers are still willing to buy. Doing this, it uses a strategy which bears some resemblance to introductory pricing, since it sets a lower price in the initial period than in the subsequent one. In order to signal quality by price alone, $H$ would have to set a higher (constant) price, implying a smaller demand and then smaller sales in the two periods. Such a strategy becomes more costly when $H$, becoming more efficient in producing quality, has a higher second-period margin and suffers accordingly more from a restricted market share.

In order to better understand why it becomes more profitable in Zone III to set a low price and to impose efficient rationing on customers rather than signalling by price alone, it is useful to evaluate the effect of a sales restriction, using Equation (12). In Zone III, as well as in Zone II, both types of firms are second-period constrained and, accordingly

$$
\begin{aligned}
\frac{\partial \Pi\left(P_{1}, \theta^{*}, H, 1\right)}{\partial \theta^{*}}= & \left(c_{H}-c_{L}\right)(1+\beta) \\
& +\beta\left(q_{H}-q_{L}\right)\left(1-2 \theta^{*}\right) .
\end{aligned}
$$

The first term is the two-period positive costdifferential effect, which has already been labelled 'profit margin effect' when referring to the first period alone. The second term is a second-period quality differential effect, stemming from the fact that $\mathrm{H}$ may then charge to now informed customers a greater price than L, the second-period price differential reflecting the quality differential. It is negative in the relevant range of values of $\theta^{*}$ (remember that both $\theta_{H}$ and $\theta_{L}$ are higher than $1 / 2$ ) and all the more negative in so far as sales are more restricted (i.e. $\theta^{*}$ is higher). To understand when signalling by price alone becomes dominated by a low price/efficient rationing strategy, one needs to evaluate Equation (13) at the sales level corresponding to signalling by price alone, i.e. at $\theta^{*}=\hat{\theta}$. As $\theta_{A}$, in Proposition 3, is the value at which the effect of sales restriction cancels, the results follow: efficient rationing cum low initial price takes over from signalling by price alone when $\hat{\theta}>\theta_{A}$, i.e. when $\lambda<\widetilde{\lambda}$. Also the intuition becomes clearer: with respect to rationing by price alone, this strategy allows the price differential of a high quality firm relative to a low quality firm to be put to advantage through a higher second-period market share.

This explains why there is a critical value of the cost ratio below which a lower price together with an effective limitation of its distribution channel become more profitable than pure price signalling. Firm $H$ 's strategy is then to sell more, in the second period in which it can raise its price, than under pure price signalling, without inducing a low quality firm to mimic it. This is made possible by setting an initial price lower than the market clearing level, implying a limitation of the distribution channel. This dissuades mimicking since only $H$ will be able to subsequently charge a second-period high price for a high quality product. Paradoxically, low initial prices associated with the initial exclusion of potential customers allow the firm to sell more in both periods with respect to signalling by price alone. Thus, when the cost/quality ratio of a high quality firm is not too great compared with the cost/quality ratio of a low quality firm then it becomes profitable to signal quality by excluding some would-be customers.

\footnotetext{
${ }^{39}$ Remark that the equilibrium in Zone III (resp. IV) corresponds to Case A (resp. B) of Proposition 1: the price is higher (lower) and the sales smaller (larger) than the low quality firm's equilibrium ones.
} 
Proposition 3 shows that, when $\lambda \in 1, \widetilde{\lambda}), \lambda \neq \bar{\lambda}$, it is optimal to signal quality by an effective initial limitation of sales and a low first-period price. In this range, signalling by price alone, when feasible, is here dominated by the 'rationing' strategy which enables the firm to earn higher profits. But whereas signalling in general is only impossible for $\lambda=\bar{\lambda}$, signalling by price alone is not possible in a whole neighbourhood of $\bar{\lambda}^{40}$ so that posting a low price and excluding some would-be consumers is the only way in that case to signal high quality. Considering for instance Zone III, the intuition is that signalling by price alone would imply such a high price yielding so little sales that the high quality firm would prefer to be mistaken for a low quality one in the first period since, in this way, it ensures for itself a higher number of consumers than in the case of signalling only by price to which it can apply, once recognized as being of high quality, a higher second-period price.

\section{Equilibrium output and price comparisons}

Not surprisingly, since this is an obvious corollary of Lemma 1, H's equilibrium output is lower than L's and H's equilibrium first-period price is higher in Zones I-III (Case A) while the reverse holds in Zone IV (Case B). This is pictured more precisely in Figures 2 and $3 .^{41}$

Proposition 4 summarizes some of our results by systematically comparing output and price levels of the high quality firm with their full-information values.

Proposition 4: The high-quality firm's equilibrium market share $\left(1-\bar{\theta}^{*}\right)$ is lower than its full-information market share $\left(1-\theta_{H}\right)$ for all $\left.\lambda \in 1, \hat{\lambda}\right]$. It is decreasing in $\lambda$ for all $\lambda \in 1, \tilde{\lambda}]$ and increasing for all $\lambda \in \tilde{\lambda}, \widehat{\lambda}]$. There exists $\left.\lambda_{c} \in\right] \bar{\lambda}, \tilde{\lambda}$ [such that the high-quality firm's equilibrium price $\bar{P}_{1}$ is lower than its full-information price $P_{H}$ for all $\lambda \in 1, \lambda_{c}$, higher for $\left.\lambda \in \lambda_{c}, \hat{\lambda}\right]$ and equal to it for all $\lambda \geq \hat{\lambda}$.

Recall that it is shown in Claim 1 that $\lambda_{c} \rightarrow k$ as $k \rightarrow$ 1 and that $\lambda_{c}<k$ at least in a right neighbourhood of $k=1$.
Not surprisingly, a high quality firm, when it has to signal quality, i.e. when the full-information pair is not a separating equilibrium, sells less than at a full-information equilibrium. However, the gap between the two does not vary in a monotonic way as the cost ratio decreases: it increases with $\lambda$ when signalling is by price alone (Zone II) and then decreases with $\lambda$ when signalling is both by price and by limitation of sales (Zones III and IV). The difference between the equilibrium price and its fullinformation value evolves in a parallel way: first increasing (Zone II) with $\lambda$ and then decreasing (Zones III and IV). These contrasted evolutions of equilibrium supply and price when signalling is only by price or when it is by price and 'rationing' show that the possibility of not serving all the potential demand paradoxically allows higher levels of sales to be reached. Moreover, the high quality firm's price is higher than its full-information value only in Zone II (Figure 4), and by continuity, at least in part of Zone III. It becomes lower than it is elsewhere. Here again, the similarity with introductory pricing is striking.

It is interesting to compare these results with those obtained in the non-dissipative advertising literature (Zhao 2000; Orzach, Overgaard, and Tauman 2002; Bagwell and Overgaard, 2005), with which there exist great similarities since both non-dissipative advertising and tailoring the distribution network affect the level of sales. All these papers, similarly to us, ${ }^{42}$ conclude that the high quality firm lowers its advertising spending with respect to its complete information level, ${ }^{43}$

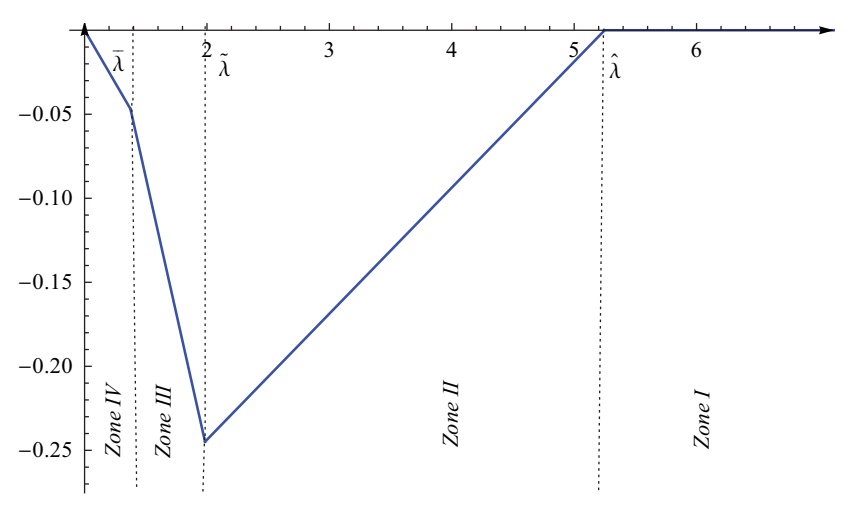

Figure 4. $\left(1-\bar{\theta}^{*}\right)-\left(1-\theta_{H}\right)$ w.r.t $\lambda$.

\footnotetext{
${ }^{40}$ The formal argument is that at $\lambda=\bar{\lambda}$, $\mathrm{H}^{\prime} \mathrm{s}$ isoprofit curve corresponding to $I C 1$ is tangent to $\mathrm{L}^{\prime} \mathrm{s}$ corresponding to $I C 2$ at $\theta=\theta_{L}$ and above everywhere else, implying that the intersection points between the latter and the $P C$ curve, which are the two candidates for being separating equilibria when $P C$ is binding, are strictly below the former and accordingly do not satisfy $I C 1$. By continuity this must also be true in a neighbourhood.

${ }^{41}$ Figures $2-5$ are drawn for the following parameter values: $\beta=0.6, b_{L}=0.3, k=2$ and $q_{L}=1$.

${ }^{42}$ Except in Zone I where the full-information equilibrium is the LCSE.

${ }^{43}$ In Zhao this is obtained if, according to our notations, $b_{H}>b_{L}$.
} 


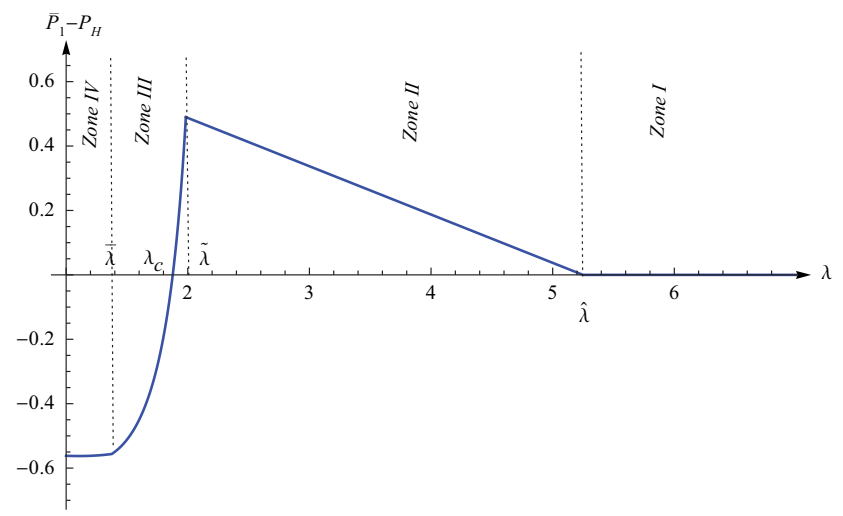

Figure 5. $\bar{P}_{1}-P_{H}$ w.r.t $\lambda$.

thereby reducing its sales. But these papers also obtain the more striking conclusion that the high quality firm advertises less than the low quality one. By contrast, in our article, the equivalent of this 'modest advertising' outcome obtains if and only if $\lambda>\bar{\lambda}$, i.e. in Case A (targeting elites) of increasing or slightly decreasing cost of quality. We obtain the opposite result iff $\lambda<\bar{\lambda}$, i.e. in Case B of steeply decreasing cost of quality. The intuition between these divergent results lies, in our two-period framework, in the interplay between the usual 'profit margin effect' and the new 'sales constraint effect', the latter becoming prevalent in Case B (mass selling).

Regarding the equilibrium prices, Zhao (2000), Bagwell and Overgaard (2005), Kim (2002) as well as Bandyopadhyay, Dongy, and Qinz (2010) prove that the high quality firm charges a price that is always higher than L's full-information price $P_{L}$. In our article, however, this holds true iff the cost of quality is increasing or slightly decreasing but the reverse obtains for a steeply decreasing cost of quality. These results are explained by the presence in our model of the 'sales constraint effect'. Zhao (2000) and Bagwell and Overgaard (2005) find that H's equilibrium price $P_{1}$ is higher than its full-information value ${ }^{44} P_{H}$. In Orzach, Overgaard, and Tauman (2002), the two are equal. In our article, as we have shown, it turns out that $P_{1}=P_{H}$ for a steeply increasing cost of quality (Orzach et al.'s result), that $P_{1}$ is unambiguously lower than $P_{H}$ for a significantly decreasing cost of quality, namely in Zone IV and the lower part of Zone III and that it is higher than $P_{H}$ in between, i.e. in Zone II and the upper part of Zone III (Zhao and Bagwell and
Overgaard's result). The case $P_{1}<P_{H}$ is to our knowledge somewhat original in the literature.

\section{Conclusion}

This article provides a tentative answer to a simple question: when should a monopolist, launching a new product, sell it through a selective distribution network where only a subset of consumers may possibly buy it? Clearly, when a high quality firm is much more inefficient than a low quality firm in producing quality, i.e. when the cost/quality ratio of a high quality firm is substantially higher than the cost/quality ratio of a low quality one, it should not use a selective distribution network since this does not bring it more profits. In this case, signalling by (a high) price alone, and accordingly selling to all buyers ready to buy at that price, is the best strategy for a high quality firm. It is not necessary to sell the good in upscale stores alone. On the contrary, a high quality firm that is slightly less efficient or more efficient than a low quality one in producing quality, so that it would be very costly to signal quality by a high price, should tailor its distribution network in order to sell its product to a selected subset of consumers with greater willingness to pay (efficient rationing). This would allow it to initially set a lower price in order to attract more customers, to whom a higher price will be subsequently charged. The low initial price is here intended to discourage mimicking while allowing a higher market for the good to be ensured than under signalling by price alone. This takes the form of an introductory price reserved for a subset of consumers. Many interesting extensions remain to be investigated. An interesting extension is to embed our model into a setting with different firm types such as a duopoly or an oligopoly case to investigate the strategic interactions between competitors through signalling.

\section{Acknowledgements}

We thank Rim Lahmandi-Ayed, Tanguy Van Ypersele, Joana Resende and conference participants at the XXVII Jornadas de Economia Industrial, Murcia 2012, for helpful comments. Financial support from Groupement de Recherche en Economie Quantitative d'Aix-Marseille (GREQAM) is gratefully acknowledged.

\footnotetext{
${ }^{44}$ In Zhao this holds true if the cost of quality is increasing.
} 


\section{Disclosure statement}

No potential conflict of interest was reported by the authors.

\section{Funding}

Financial support from Groupement de Recherche en Économie Quantitative d'Aix-Marseille (GREQAM) is gratefully acknowledged.

\section{References}

Bagwell, K., and P. B. Overgaard. 2005. "Look How Little I'm Advertising!” CIE Discussion Papers, Department of Economics, Center for Industrial Economics, n:2005-02. University of Copenhagen.

Bandyopadhyay, T., B. Dongy, and C. Z. Qinz. 2010. "Limit Supplying as a Signal of Quality”, http://www.saet.illinois. edu/papers_and_talks/event-04/Bandyopadhyay-DongQin.pdf

Cho, I. K., and D. M. Kreps. 1987. "Signaling Games and Stable Equilibria." The Quarterly Journal of Economics 102 (2): 179-221. doi:10.2307/1885060.

Franklin, A., and G. R. Faulhaber. 1990. "Rational Rationing." Economica 58: 189-198.

Gonzalez, J. L. M. 2000. "Quality Uncertainty and Informative Advertising." International Journal of

\section{Appendix}

Lemma 2: From the constraint IC2 and the Implicit Function Theorem, the maximum possible initial price $P_{1}$ is an increasing convex function $G$ of the critical consumer type $-\theta^{*}$ Accordingly, it is tangent to $P_{1}=\theta^{*} q_{L}$ at $\left(P_{L}, \theta_{L}\right)$ and above at any other point, i.e. $G\left(\theta^{*}\right)>\theta^{*} q_{L}, \forall \theta^{*} \neq \theta_{L}$.

Proof of Lemma 2: The incentive constraint IC2 (given by Expression (IC2)) may be written as

$$
\left\{\begin{array}{lll}
P_{1} \leq q_{L}\left((1+\beta) \frac{\left(1-b_{L}\right)^{2}}{4\left(1-\theta^{*}\right)}-\beta\left(\theta^{*}-b_{L}\right)+b_{L}\right)=P_{1(\max )} & \text { if } \quad \theta^{*} \geq \frac{b_{L}+1}{2} \\
P_{1} \leq q_{L}\left(\frac{1}{4} \frac{\left(b_{L}-1\right)^{2}}{\left(1-\theta^{*}\right)}+b_{L}\right)=P_{1(\max )} & \text { if } \quad \theta^{*}<\frac{b_{L}+1}{2}
\end{array}\right.
$$

Note that, in both cases, $\frac{\partial^{2}}{\partial \theta^{* 2}} P_{1(\max )}>0$, and since $G$ is continuously differentiable at $\theta^{*}=\frac{b_{L}+1}{2}$, it is a convex function.

- When $\theta^{*} \leq \frac{b_{L}+1}{2}, \frac{\partial}{\partial \theta^{*}} P_{1(\max )}=\frac{q_{L}\left(b_{L}-1\right)^{2}}{4(\theta-1)^{2}}>0$.

- When $\theta^{*} \geq \frac{b_{L}+1}{2}, \frac{\partial}{\partial \theta^{*}} P_{1(\max )}$ has the same sign as

$$
-\left(4 \theta^{2} \beta-8 \theta \beta+2 \beta b_{L}+3 \beta+2 b_{L}-b_{L}^{2}-\beta b_{L}^{2}-1\right),
$$

which is positive for all
Industrial Organization 18: 615-640. doi:10.1016/S01677187(98)00034-4.

Kim, J.-Y. 2002. "Rationing as a Signal." International Journal of Business and Economics 1 (2): 115-122.

Marvel, H. P., and S. McCafferty. 1984. "Resale Price Maintenance and Quality Certification." The RAND Journal of Economics 15 (3): 346-359. doi:10.2307/ 2555443.

Milgrom, P., and J. Roberts. 1986. "Price and Advertising Signals of Product Quality." Journal of Political Economy 94 (4): 796-821. doi:10.1086/261408.

Nelson, P. 1974. “Advertising as Information”, Journal of Political Economy, Vol. 82, 729-753.

Orzach, R., P. B. Overgaard, and Y. Tauman. 2002. "Modest Advertising Signals Strength." The RAND Journal of Economics 33 (2): 340-358. doi:10.2307/ 3087437.

Radner, R. 2003. "Viscous Demand.” Journal of Economic Theory 112: 189-231. doi:10.1016/S0022-0531(03) 00115-7.

Stock, A., and S. Balachander. 2005. "The Making of A "Hot Product": A Signaling Explanation of Marketers' Scarcity Strategy." Management Science 51 (8): 1181-1192. doi:10.1287/mnsc.1050.0381.

Zhao, H. 2000. "Raising Awareness and Signaling Quality to Uninformed Consumers: A Price Advertising Model." Marketing Science 19 (4): 390-396. doi:10.1287/ mksc.19.4.390.11788.

$\theta^{*} \in\left[\frac{\left(2 \beta-\left(1-b_{L}\right) \sqrt{\beta(\beta+1)}\right)}{2 \beta}, \frac{\left(2 \beta+\left(1-b_{L}\right) \sqrt{\beta(\beta+1)}\right)}{2 \beta}\right]$

Moreover, it can be checked that:

$\frac{\left(2 \beta-\left(1-b_{L}\right) \sqrt{\beta(\beta+1)}\right)}{2 \beta}<\frac{b_{L}+1}{2}<1<\frac{\left(2 \beta+\left(1-b_{L}\right) \sqrt{\beta(\beta+1)}\right)}{2 \beta}$.

Thus, $\frac{\partial}{\partial \theta^{*}} P_{1(\max )}>0$ for all $\theta^{*} \geq \frac{b_{L}+1}{2}$.

Proof of Lemma 1: Let us define the set $T$ as including all the pairs $\left(P_{1}, \theta^{*}\right)$ that satisfy the constraints $I C 2, P C$ and the constraint

$$
\Pi\left(P_{1}, \theta^{*}, H, 1\right) \geq \Pi\left(q_{L} \frac{1+b_{L}}{2}, \frac{1+b_{L}}{2}, H, 0\right)
$$

(ICX)

where the RHS is firm H's profit when it mimics the low quality firm's strategy.

Remark that $T$ includes all couples which, under the most favourable beliefs, give to $H$ a higher profit and to $L$ a lower profit than does $\left(P_{L}, \theta_{L}\right)$, which is the pair that maximizes $L$ 's profits when it is perceived as a low quality firm. By choosing a couple $\left(P_{1}, \theta^{*}\right) \in T$ other than $\left(P_{L}, \theta_{L}\right)$, the firm unambiguously signals high quality. All separating equilibria belong to $T$ (see Remark below) though all couples in $T$ are not separating equilibria. 
Remark 2: Since $\Pi\left(q_{L} \frac{1+b_{L}}{2}, \frac{1+b_{L}}{2}, H, 0\right) \leq \Pi\left(\theta_{H L} q_{L}, \theta_{H L}\right.$, $H, 0)$, the set $S$ of separating equilibria is a subset of $T$. Moreover $\left(P_{L}, \theta_{L}\right)$ always belongs to $T$, since at this pair the two constraints IC2 and ICX are trivially satisfied with equality while the participation condition PC is satisfied with strict inequality.

In this proof, in order to characterize the set of separating equilibria, we shall rely on the fact that it is a subset of the set $T$.

A. Existence: We provide an existence proof for values of $\lambda \neq \bar{\lambda}$ which amounts showing that $\left(P_{H L}, \theta_{H L}\right)$ is then always a separating equilibrium. The proof that no separating equilibrium exists when $\lambda=\bar{\lambda}$ is available upon request from the authors.

Iff $\lambda \neq \bar{\lambda}, \quad\left(P_{H L}, \theta_{H L}\right) \neq\left(P_{L}, \theta_{L}\right)$. It is then easy to see that $\left(P_{H L}, \theta_{H L}\right)$ is a separating equilibrium since (i) it trivially satisfies IC1, (ii) from the convexity of $G, P_{H L}=$ $\theta_{H L} q_{L}<G\left(\theta_{H L}\right)$ so that IC2 is satisfied and (iii) $P_{H L}=$ $\theta_{H L} q_{L}<\theta_{H L} q_{H}$ so that $P C$ is also satisfied.

B. Characterization We shall first show that (i) in Case $\mathrm{A}$, if a couple $\left(P_{1}, \theta^{*}\right)$ belongs to $\mathrm{T}$ it must be that $\theta^{*} \geq$ $\frac{b_{L}}{2}+\frac{1}{2}$ and (ii) in Case $\mathrm{B}$, if a couple $\left(P_{1}, \theta^{*}\right)$ belongs to $\mathrm{T}$ it must be that $\theta^{*} \leq \frac{b_{L}}{2}+\frac{1}{2}$. Of course, since the set $S$ of separating equilibria is a subset of $T$, these results hold true as well for couples $\left(P_{1}, \theta^{*}\right) \in S$. These results obtained, the comparisons of $P_{1}$ with $P_{L}$ follow. Indeed, in Case $\mathrm{A}$, $\left(P_{1}, \theta^{*}\right) \in S \Rightarrow P_{1}>\theta^{*} q_{L}$ and, from $\theta^{*}>\theta_{L}$, we obtain $P_{1}>\theta_{L} q_{L}=P_{L}$. In Case $\mathrm{B}, \quad\left(P_{1}, \theta^{*}\right) \in S \Rightarrow P_{1} \leq G\left(\theta^{*}\right)$. Since $G$ is increasing, from $\theta^{*}<\theta_{L}$ we obtain $P_{1}<G\left(\theta_{L}\right)=P_{L}$.

(1) In the increasing cost case, if $\theta^{*} \leq \frac{b_{L}}{2}+\frac{1}{2}$, $\left(P_{1}, \theta^{*}\right) \in T$ implies that

$$
\left\{\begin{array}{ll}
P_{1} \geq \frac{1-b_{L}}{2\left(1-\theta^{*}\right)}\left(q_{L} \frac{b_{L}+1}{2}-b_{H} q_{H}\right)+b_{H} q_{H} & (\text { from ICX) } \\
P_{1} \leq \frac{q_{L}\left(b_{L}-1\right)^{2}}{4\left(1-\theta^{*}\right)}+b_{L} q_{L} & (\text { from IC2) }
\end{array},\right.
$$

which is not true since we easily verify that:

$$
\frac{1-b_{L}}{2\left(1-\theta^{*}\right)}\left(q_{L} \frac{b_{L}+1}{2}-b_{H} q_{H}\right)+b_{H} q_{H}>\frac{q_{L}\left(b_{L}-1\right)^{2}}{4\left(1-\theta^{*}\right)}+b_{L} q_{L} .
$$

We conclude that $\left(P_{1}, \theta^{*}\right) \in S \sqsubseteq T \Rightarrow \theta^{*}>\frac{b_{L}}{2}+\frac{1}{2}$.

\section{(2) In the decreasing cost case,}

(a) For $\frac{b_{H}}{2}+\frac{1}{2} \leq \theta^{*} \leq \frac{b_{L}}{2}+\frac{1}{2}$, we must have:

$$
\begin{cases}P_{1} \geq \frac{1-b_{L}}{2\left(1-\theta^{*}\right)}\left[(1+\beta)\left(q_{L} \frac{b_{L}+1}{2}-b_{H} q_{H}\right)\right. & \\ \left.+\beta \frac{1+b_{L}}{2}\left(q_{H}-q_{L}\right)\right]-\beta\left(\theta^{*} q_{H}-b_{H} q_{H}\right)+b_{H} q_{H} & (\text { from ICX). } \\ P_{1} \leq \frac{q_{L}\left(b_{L}-1\right)^{2}}{4\left(1-\theta^{*}\right)}+b_{L} q_{L} & \text { (from IC2) }\end{cases}
$$

This is possible simultaneously iff:

$$
\begin{gathered}
\frac{1-b_{L}}{2\left(1-\theta^{*}\right)}\left[(1+\beta)\left(q_{L} \frac{b_{L}+1}{2}-b_{H} q_{H}\right)+\beta \frac{1+b_{L}}{2}\left(q_{H}-q_{L}\right)\right] \\
-\beta\left(\theta^{*} q_{H}-b_{H} q_{H}\right)+b_{H} q_{H} \leq P_{1} \leq \frac{q_{L}\left(b_{L}-1\right)^{2}}{4\left(1-\theta^{*}\right)}+b_{L} q_{L}
\end{gathered}
$$

i.e. iff: $B(\theta, \lambda) \geq 0$, where $B(\theta, \lambda)$ has been already defined. $B(\theta, \lambda)$ is positive only for values of $\theta$ between $\frac{b_{L}+1}{2}$ and $\frac{1}{2}+\frac{b_{L}(2 \lambda(1+\beta)-2-k \beta)}{2 k \beta}$. The second root is higher than the first iff

$$
\lambda>\frac{1+k \beta}{1+\beta} .
$$

Thus, under the condition 16 , there is no separating equilibrium such that $\frac{b_{H}}{2}+\frac{1}{2} \leq \theta^{*} \leq \frac{b_{L}}{2}+\frac{1}{2}$.

(b) For $\theta^{*} \leq \frac{b_{H}}{2}+\frac{1}{2} \leq \frac{b_{L}}{2}+\frac{1}{2}$, we must have

$$
\begin{cases}P_{1} \geq \frac{1-b_{L}}{2\left(1-\theta^{*}\right)}\left[(1+\beta)\left(q_{L} \frac{b_{L}+1}{2}-b_{H} q_{H}\right)\right. & \\ \left.+\beta \frac{1+b_{L}}{2}\left(q_{H}-q_{L}\right)\right]-\beta q_{H} \frac{\left(1-b_{H}\right)^{2}}{4\left(1-\theta^{*}\right)}+b_{H} q_{H} & (\text { from ICX) } . \\ P_{1} \leq \frac{q_{L}\left(b_{L}-1\right)^{2}}{4\left(1-\theta^{*}\right)}+b_{L} q_{L} & (\text { from IC2) }\end{cases}
$$

This is possible simultaneously iff

$$
\begin{aligned}
& \frac{1-b_{L}}{2\left(1-\theta^{*}\right)}\left[(1+\beta)\left(q_{L} \frac{b_{L}+1}{2}-b_{H} q_{H}\right)+\beta \frac{1+b_{L}}{2}\left(q_{H}-q_{L}\right)\right] \\
& \quad-\beta q_{H} \frac{\left(1-b_{H}\right)^{2}}{4\left(1-\theta^{*}\right)}+b_{H} q_{H} \\
& \quad \leq P_{1} \leq \frac{q_{L}\left(b_{L}-1\right)^{2}}{4\left(1-\theta^{*}\right)}+b_{L} q_{L},
\end{aligned}
$$

i.e. iff $A(\theta, \lambda) \geq 0$, where $A(\theta, \lambda)$ has been already defined. We also remarked that $A\left(\frac{1+b_{H}}{2}, \lambda\right)=B\left(\frac{1+b_{H}}{2}, \lambda\right)$. Moreover the sign of $A$ is the sign of a first order polynomial which is increasing in $\theta$. From that and point (a) above, we conclude that for $\lambda>\frac{1+k \beta}{1+\beta}$ we have $A\left(\frac{1+b_{H}}{2}, \lambda\right)=B\left(\frac{1+b_{H}}{2}, \lambda\right)<0$ which implies $A(\theta, \lambda)<0$ for all $\theta^{*} \leq \frac{b_{H}}{2}+\frac{1}{2}$. Then there are no separating equilibria such that $\theta^{*} \leq \frac{b_{L}}{2}+\frac{1}{2}$ when $\lambda>\frac{1+k \beta}{1+\beta}$.

(c) Finally, for $\theta^{*} \geq \frac{b_{L}}{2}+\frac{1}{2}$ we must have

$$
\begin{cases}P_{1} \geq \frac{1-b_{L}}{2\left(1-\theta^{*}\right)}\left[(1+\beta)\left(q_{L} \frac{b_{L}+1}{2}-b_{H} q_{H}\right)\right. & \\ \left.+\beta \frac{1+b_{L}}{2}\left(q_{H}-q_{L}\right)\right]-\beta\left(\theta^{*} q_{H}-b_{H} q_{H}\right)+b_{H} q_{H} & (\text { from ICX }) . \\ P_{1} \leq(1+\beta) q_{L} \frac{\left(1-b_{L}\right)^{2}}{4\left(1-\theta^{*}\right)}-\beta q_{L}\left(\theta^{*}-b_{L}\right)+b_{L} q_{L} & (\text { from IC2) }\end{cases}
$$

This is possible simultaneously iff

$$
\begin{aligned}
& \frac{1-b_{L}}{2\left(1-\theta^{*}\right)}\left[(1+\beta)\left(q_{L} \frac{b_{L}+1}{2}-b_{H} q_{H}\right)+\beta \frac{1+b_{L}}{2}\left(q_{H}-q_{L}\right)\right] \\
& -\beta\left(\theta^{*} q_{H}-b_{H} q_{H}\right)+b_{H} q_{H} \leq P_{1} \leq(1+\beta) q_{L} \frac{\left(1-b_{L}\right)^{2}}{4\left(1-\theta^{*}\right)} \\
& \quad-\beta q_{L}\left(\theta^{*}-b_{L}\right)+b_{L} q_{L}
\end{aligned}
$$

i.e. iff $C(\theta, \lambda) \geq 0$, where $C(\theta, \lambda)$ has already been defined. $C(\theta, \lambda)$ is positive only for values of $\theta$ between $\frac{b_{L}+1}{2}$ and $\frac{1}{2}+\frac{b_{L}(2(1+\beta) \lambda-2-\beta(1+k))}{2 \beta(k-1)}$. The second root is lower than the first when $\lambda<\frac{1+k \beta}{1+\beta}$. There are then no separating equilibria such that $\theta^{*} \geq \frac{b_{L}}{2}+\frac{1}{2} \quad$ when $\quad \lambda<\frac{1+k \beta}{1+\beta}$. height .9ex width .8ex depth -.1 ex

Proof of Proposition 1: To be a separating equilibrium, the couple $\left(P_{1}, \theta^{*}\right)=\left(\frac{q_{H}\left(1+b_{H}\right)}{2}, \frac{1}{2}+\frac{b_{H}}{2}\right)$ must satisfy IC1 and IC2. 
It is straightforward that $P C$ is satisfied. It is also obvious that this couple cannot satisfy $I C 2$ when $b_{H} \leq b_{L}$ (decreasing cost of quality). Let us then consider only the case of increasing cost of quality and let us only check whether the constraints $I C 1$ and IC2 are satisfied.

(1) The constraint IC1 writes as $\frac{\left(1-b_{H}\right)^{2}}{4}(1+\beta) q_{H} \geq$ $q_{L} \frac{\left(1+k \beta-(1+\beta) \lambda b_{L}\right)^{2}}{4(1+k \beta)}$, i.e. $\frac{\left(1-b_{H}\right)^{2}}{4} q_{H} \geq\left(\frac{1}{2}-\frac{b_{L}}{2}\right)\left(\frac{1+b_{L}}{2} q_{L}-\right.$ $\left.b_{H} q_{H}\right)$. This is obviously true since $\frac{\left(1-b_{H}\right)^{2}}{4} q_{H}=$ $\max _{\theta^{*}}\left(1-\theta^{*}\right)\left(\theta^{*} q_{H}-b_{H} q_{H}\right) \geq \max _{\theta^{*}}\left(1-\theta^{*}\right)\left(\theta^{*} q_{L}-\right.$ $\left.b_{H} q_{H}\right)$.

(2) The constraint IC2 can be expressed as $\left(\frac{1-b_{L}^{2}}{4}\right)(1+$ $\beta) q_{L} \geq\left(\frac{1}{2}-\frac{b_{H}}{2}\right)\left(\left(q_{H} \frac{1+b_{H}}{2}-b_{L} q_{L}\right)+\beta q_{L}\left(\frac{1+b_{H}}{2}-b_{L}\right)\right)$ or, equivalently

$$
\hat{\lambda}=k \frac{b_{L}+\sqrt{(k-1)\left(k+\beta-b_{L}^{2}-\beta b_{L}^{2}\right)}+\beta b_{L}}{b_{L}(k+\beta)}>k .
$$

Proof of Propositions 2 and 3: Let us define:

$$
\tilde{\lambda}=\frac{k(1+\beta)^{2} b_{L}+\sqrt{\beta^{2}(k-1)^{3}\left(k+\beta-(1+\beta) b_{L}^{2}\right)}}{(1+\beta)(k+\beta) b_{L}},
$$

The following Claim is useful to establish a regioning of the four different types of LCSE in the space $(k, \lambda)$.

\section{Claim 1}

(i) $\bar{\lambda}<\widetilde{\lambda}<\widehat{\lambda}$

(ii) $\bar{\lambda}<k<\hat{\lambda}$,

(iii) there is always a right neighbourhood of $k=$ 1 where $\tilde{\lambda}<k$,

(iv) there is always a right neighbourhood of $k=$ 1 where $\lambda_{c}<k$,

with

Proof of Claim 1: (i) $\tilde{\lambda}-\widehat{\lambda}$ has the same sign as

$$
\begin{aligned}
& \sqrt{\beta^{2}(k-1)^{3}\left(k+\beta-(1+\beta) b_{L}^{2}\right)} \\
& -k(1+\beta) \sqrt{(k-1)\left(k+\beta-b_{L}^{2}-\beta b_{L}^{2}\right)}
\end{aligned}
$$

Evaluating the difference between the squares of the two terms gives:

$$
(k-1)(-k-\beta(2 k-1))(k+\beta)\left(k-b_{L}^{2}+\beta\left(1-b_{L}^{2}\right)\right)<0 .
$$

Moreover, $\widetilde{\lambda}-\bar{\lambda}$ has the same sign as

$$
-b(k-1)^{2} \beta+\sqrt{(k-1)^{3} \beta^{2}\left(k+\beta-b_{L}^{2}(1+\beta)\right)} .
$$

Evaluating the difference between the squares of the two terms gives:

$$
\left(1-b^{2}\right)(k-1)^{3} \beta^{2}(k+\beta)>0 .
$$

(ii) $k>\bar{\lambda}=\frac{1+k \beta}{1+\beta}$ since $k>1$.

Moreover, $\hat{\lambda}-k$ has the same sign as

$-b_{L}(k-1)+\sqrt{-k-\beta+k \beta+b_{L}^{2}-k b_{L}^{2}+\beta b_{L}^{2}+k^{2}-k \beta b_{L}^{2}}$.

Evaluating the difference between the squares of the two terms gives

$$
\left(1-b_{L}^{2}\right)(k-1)(k+\beta)>0 .
$$

(iii) $\tilde{\lambda}-k$ has the same sign as

$$
-(k-1) k(1+\beta) b_{L}+\sqrt{(k-1)^{3} \beta^{2}\left(k+\beta-(1+\beta) b_{L}^{2}\right.}
$$

Evaluating the difference between the squares of the two terms gives

$\mathcal{F}(k)=-(k-1)^{2}(k+\beta)\left(\left(b_{L}^{2}(\beta+1)^{2}-\beta^{2}\right) k+\beta\left(\beta-b_{L}^{2}(\beta+1)\right)\right)$

$\mathcal{F}$ is a fourth-order polynomial in $k$. It can be seen that $\mathcal{F}(1)=0, \quad \mathcal{F}^{\prime}(1)=0 \quad$ and $\quad \mathcal{F}^{\prime \prime}(1)=-2(1+\beta)^{2} b_{L}^{2}<0$ : there is a local maximum at $k=1$; Moreover $\mathcal{F}(k)=0$ has three roots: $k=-\beta, \quad k=\frac{\beta\left(b_{L}^{2}(1+\beta)-\beta\right)}{-\beta^{2}+(1+\beta)^{2} b_{L}^{2}}$ and $k=1$ (double root). Accordingly, either $\quad \frac{\beta\left(b_{L}^{2}(1+\beta)-\beta\right)}{-\beta^{2}+(1+\beta)^{2} b_{L}^{2}} \leq 1$ $\left(\Leftrightarrow-\beta+(1+\beta) b_{L} \geq 0\right)$, in which case $\mathcal{F}(k)<0$ for $\forall k>1$, or $\frac{\beta\left(b_{L}^{2}(1+\beta)-\beta\right)}{-\beta^{2}+(1+\beta)^{2} b_{L}^{2}}>1 \quad\left(\Leftrightarrow-\beta+(1+\beta) b_{L}<0\right)$, in which case $\mathcal{F}(k)<0$ for $\forall k \in\left(1, \frac{\beta\left(b_{L}^{2}(1+\beta)-\beta\right)}{-\beta^{2}+(1+\beta)^{2} b_{L}^{2}}\right)$ and $\mathcal{F}(k)>0 \quad \forall k>\frac{\beta\left(b_{L}^{2}(1+\beta)-\beta\right)}{-\beta^{2}+(1+\beta)^{2} b_{L}^{2}}$.

(iv) $\lambda_{c}-k$ has the same sign as

Evaluating the difference between the squares of the two terms gives:

$$
\begin{aligned}
\Gamma(k)= & -4(k-1)^{2}(1+\beta)(k+\beta) b_{L}^{2}(-(k-1) \beta \\
& \left.+b_{L}\left(k+(k-1)(1+\beta) b_{L}\right)\right) .
\end{aligned}
$$

$\Gamma$ is a fourth-order polynomial in $k$. We see that $\Gamma(1)=0$, $\Gamma^{\prime}(1)=0$ and $\Gamma^{\prime \prime}(1)=-8(1+\beta)^{2} b_{L}^{3}<0$ : there is a local maximum at $k=1$; Moreover $\Gamma(k)=0$ has three roots: $k=$ $-\beta, \quad k=\frac{-\beta+b_{L}^{2}(1+\beta)}{\left(1+b_{L}\right)\left(-\beta+b_{L}(1+\beta)\right)} \quad$ and $\quad k=1 \quad$ (double root). $\lambda_{c}=\frac{\left(-(-1+k)(k+\beta) b_{L}+(1+\beta)(-1+k(3+2 \beta)) b_{L}^{2}+\sqrt{ }\left((-1+k)^{2} b_{L}^{2}\left((k+\beta)\left(k(1+2 \beta)^{2}-\beta(3+4 \beta)\right)+(1+\beta) b_{L}\left(-2(k+\beta)-(1+\beta)(-1+4(-1+k) \beta) b_{L}\right)\right)\right)\right)}{\left(2(1+\beta)(k+\beta) b_{L}^{2}\right)}$ 


$$
\begin{aligned}
& (k-1) b_{L}\left(-k-\beta-(2 k-1)(1+\beta) b_{L}\right. \\
& \quad+\sqrt{\left.(k-1)^{2} b_{L}^{2}\left((k+\beta)\left(k(1+2 \beta)^{2}-\beta(3+4 \beta)\right)+(1+\beta) b_{L}\left(-2(k+\beta)-(1+\beta)(-1+4(k-1) \beta) b_{L}\right)\right)\right)}
\end{aligned}
$$

Accordingly, either $\quad \frac{-\beta+b_{L}^{2}(1+\beta)}{\left(1+b_{L}\right)\left(-\beta+b_{L}(1+\beta)\right)} \leq 1 \quad(\Leftrightarrow-\beta+$ $\left.(1+\beta) b_{L} \geq 0\right)$, in which case $\Gamma(k)<0$ for $\forall k>1$, or $\frac{-\beta+b_{L}^{2}(1+\beta)}{\left.1+b_{L}\right)\left(-\beta+b_{L}(1+\beta)\right)}>1 \quad\left(\Leftrightarrow-\beta+(1+\beta) b_{L}<0\right)$, in which case $\Gamma(k)<0$ for $\forall k \in\left(1, \frac{-\beta+b_{L}^{2}(1+\beta)}{\left(1+b_{L}\right)\left(-\beta+b_{L}(1+\beta)\right)}\right)$ and $\Gamma(k)>0$ $\forall k>\frac{-\beta+b_{L}^{2}(1+\beta)}{\left(1+b_{L}\right)\left(-\beta+b_{L}(1+\beta)\right)}$.

At any LCSE, at least one of the two constraints must bind. From Lemma 2, the equilibrium pair $\left(P_{1}, \theta^{*}\right)$ must maximize $\quad \Pi\left(P_{1}, \theta^{*}, H, 1\right) \quad$ subject to $\bar{P}_{1}=\min _{\theta^{*}}\left\{\theta^{*} q_{H}, G\left(\theta^{*}\right)\right\}=\Phi\left(\theta^{*}\right)$. For the sake of convenience, let us define

$$
\pi\left(\theta^{*}\right)=\Pi\left(\Phi\left(\theta^{*}\right), \theta^{*}, H, 1\right) .
$$

Accordingly, an LCSE is a pair $\left(\bar{P}_{1}, \bar{\theta}^{*}\right) \neq\left(P_{L}, \theta_{L}\right)$ such that $\bar{\theta}^{*}$ maximizes $\pi\left(\theta^{*}\right)$. Characterizing the LCSE of the game consequently amounts to bringing to light the maximands of $\pi\left(\theta^{*}\right)$. We shall consider successively Cases A and B, corresponding respectively to (i) and (ii) of Proposition 2 and (i) of Proposition 3 for Case A and to (ii) of Proposition 3 for Case B. I. Case A Since $\lambda>\frac{1+k \beta}{1+\beta}$, from Lemma 1, we only need to consider here the values of $\theta^{*} \geq \frac{1+b_{L}}{2}$. The incentive constraint (IC2) is already defined by Expression (14). The incentive constraint (IC2) and the participation constraint $(P C)$ intersect $^{45}$ at

$$
\begin{aligned}
\hat{\theta}= & \frac{k+\beta+b_{L}+\beta b_{L}+\sqrt{(k-1)\left(k+\beta-b_{L}^{2}-\beta b_{L}^{2}\right)}}{2(k+\beta)} \\
& \geq \frac{b_{L}+1}{2} .
\end{aligned}
$$

Let us study how $\pi$ changes with $\theta^{*}$ over the interval $\left(\frac{1+b_{L}}{2}, 1\right]$. A. Over $\left(\frac{1+b_{L}}{2}, \min \left\{\frac{1+b_{H}}{2}, \hat{\theta}\right\}\right]$, of course in the increasing cost case,

Here, the constraint (IC2) is binding so that $P_{1}=G\left(\theta^{*}\right)$. This function is convex and everywhere increasing over the interval, since (i) $\frac{\partial^{2} \pi}{\partial \theta^{* 2}}=2 \beta q_{L}>0$ and (ii) $\pi$ takes its minimum value at $\theta^{*}=\frac{\beta\left(1+b_{L}\right)-k b_{H}+b_{L}}{2 \beta}<\frac{1+b_{L}}{2}$. B. Over $\left[\max \left\{\frac{1+b_{H}}{2}, \frac{1+b_{L}}{2}\right\}, \hat{\theta}\right]$, when of course this interval is not empty, $\quad \pi\left(\theta^{*}\right)=q_{L}\left(\left(1-\theta^{*}\right)\left((1+\beta) \frac{\left(1-b_{L}\right)^{2}}{4\left(1-\theta^{*}\right)}-\beta\left(\theta^{*}-b_{L}\right)\right.\right.$ $\left.\left.+b_{L}-k b_{H}\right)+k \beta\left(1-\theta^{*}\right)\left(\theta^{*}-b_{H}\right)\right)$. This function is concave, since $\frac{\partial^{2} \pi}{\partial \theta^{+2}}=-2 \beta q_{L}(k-1)<0$, and takes its maximum value at $\theta^{*}=\frac{1}{2}+\frac{b_{L}(\lambda-1)(1+\beta)}{2 \beta(k-1)}>\frac{1+b_{L}}{2}$. Moreover, $\frac{1}{2}+$ $\frac{b_{L}(1-\lambda)(1+\beta)}{2 \beta k}>\frac{1+b_{H}}{2}$, both in the decreasing cost case, because $\frac{1+b_{L}}{2} \geq \frac{1+b_{H}}{2}$, and in the increasing cost case, because $b_{L} \frac{(\lambda-1)}{(k-1)}>b_{H}$. The sign of $\frac{1}{2}+\frac{b_{L}(\lambda-1)(1+\beta)}{2 \beta(k-1)}-\hat{\theta}$ is easily shown to be the sign of $\lambda-\tilde{\lambda}$. We conclude that $\pi$ is increasing in $\theta^{*}$ over the whole interval when $\lambda \geq \tilde{\lambda}$ and takes a maximum value on this interval when $\lambda \leq \widetilde{\lambda}$. C. Over [ $\hat{\theta}, 1]$, $\pi\left(\theta^{*}\right)=k q_{L}(\beta+1)\left(1-\theta^{*}\right)\left(\theta^{*}-b_{H}\right)$ if $\theta^{*} \geq \frac{1+b_{H}}{2} \quad$ and $\pi\left(\theta^{*}\right)=k q_{L}\left(\left(1-\theta^{*}\right)\left(\theta^{*}-b_{H}\right)+\beta \frac{\left(1-b_{H}\right)^{2}}{4}\right) \quad$ if $\quad \theta^{*} \leq \frac{1+b_{H}}{2}$. These two functions are concave and take their maximum value at $\theta^{*} \leq \frac{1+b_{H}}{2}$. Notice that it is easily shown that the sign of $\frac{1+b_{H}}{2}-\hat{\theta}$ is the sign of $\lambda-\hat{\lambda}$. Then there are two cases: (i) when $\lambda \leq \hat{\lambda}, \pi$ is decreasing over the whole interval, and (ii) when $\lambda \geq \hat{\lambda}, \pi$ takes a maximum value over the interval. We can now distinguish three cases. Since, in this area where $\lambda>\frac{1+k \beta}{1+\beta}$, we always check that (a) $\frac{1+b_{L}}{2}<\hat{\theta}$, (b) $\frac{1+b_{L}}{2}<\frac{1}{2}+$ $\frac{b_{L}(\lambda-1)(1+\beta)}{2 \beta(k-1)}$, and (c) $\frac{1+b_{H}}{2}<\frac{b_{L}(\lambda-1)(1+\beta)}{2 \beta(k-1)}$, locating the maximum of $\pi$ with respect to $\theta^{*}$ amounts to locating $\frac{1+b_{H}}{2}$ and $\frac{1}{2}+\frac{b_{L}(\lambda-1)(1+\beta)}{2 \beta(k-1)}$ with respect to $\hat{\theta}$. Only three cases are possible:

(1) $\hat{\theta} \leq \frac{1+b_{H}}{2}<\frac{1}{2}+\frac{b_{L}(\lambda-1)(1+\beta)}{2 \beta(k-1)}$ or, equivalently, $\lambda \geq \hat{\lambda}$ : here we know that $\pi$ is increasing over $\left[\frac{1+b_{L}}{2}, \hat{\theta}\right]$ and then takes its unique maximum at $\frac{1+b_{H}}{2}$. The participation constraint is binding alone and the LCSE coincides with the full-information equilibrium. This corresponds to Zone I.

(2) $\frac{1+b_{H}}{2} \leq \hat{\theta} \leq \frac{1}{2}+\frac{b_{L}(\lambda-1)(1+\beta)}{2 \beta(k-1)}$ or, equivalently, $\hat{\lambda} \geq \lambda \geq$ $\tilde{\lambda}$ : Here, we now know that $\pi$ is increasing over $\left[\frac{1+b_{L}}{2}, \hat{\theta}\right]$ and then decreasing over $[\hat{\theta}, 1]$ so that it takes a unique maximum at $\hat{\theta}$. Both constraints $(P C)$ and (IC2) are binding. This corresponds to Zone II.

(3) $\frac{1+b_{H}}{2}<\frac{1}{2}+\frac{b_{L}(\lambda-1)(1+\beta)}{2 \beta(k-1)} \leq \hat{\theta}$ or, equivalently, $\lambda \leq \tilde{\lambda}$ (remember that $\lambda>\bar{\lambda}$ ); Here we know that $\pi$ takes a maximum value at $\theta^{*}=\frac{1}{2}+\frac{b_{L}(\lambda-1)(1+\beta)}{2 \beta(k-1)}$ over $\left[\frac{1+b_{L}}{2}, \hat{\theta}\right]$ and then is decreasing over $[\hat{\theta}, 1]$, so that the local maximum is a global one as well. The incentive

$$
\left.\left.\pi\left(\theta^{*}\right)=q_{L} \quad\left(1-\theta^{*}\right) \quad(1+\beta) \frac{\left(1-b_{L}\right)^{2}}{4\left(1-\theta^{*}\right)}-\beta\left(\theta^{*}-b_{L}\right)+b_{L}-k b_{H}\right)+\beta k \frac{\left(1-b_{H}\right)^{2}}{4}\right) .
$$


constraint (IC2) is binding alone. This corresponds to Zone III.

II. CASE B: Since $\lambda<\frac{1+k \beta}{1+\beta}$, from Lemma 1 , we need only to consider here the values of $\theta^{*} \leq \frac{1+b_{L}}{2}$. The incentive constraint (IC2) is already defined by Expression (14). The incentive constraint $(I C 2)$ and the participation constraint $(P C)$ intersect $^{46}$ at:

$$
\widetilde{\theta}=\frac{k+b_{L}-\sqrt{(k-1)\left(k-b_{L}^{2}\right)}}{2 k}<\frac{1+b_{H}}{2}<\frac{1+b_{L}}{2} .
$$

Let us study how $\pi$ changes with $\theta^{*}$ over the interval $\left[0, \frac{1+b_{L}}{2}\right)$.

A. Over $[0, \tilde{\theta}], \pi\left(\theta^{*}\right)=k q_{L}\left(\left(1-\theta^{*}\right)\left(\theta^{*}-b_{H}\right)+\beta \frac{\left(1-b_{H}\right)^{2}}{4}\right)$ is strictly increasing since it is a concave function which takes its maximum outside the interval, namely at $\theta^{*}=\frac{1+b_{H}}{2^{2}}>\widetilde{\theta}$.

B. Over $\left[\widetilde{\theta}, \frac{1+b_{H}}{2}\right], \pi\left(\theta^{*}\right)=q_{L}\left(\left(1-\theta^{*}\right)\left(\frac{\left(1-b_{L}\right)^{2}}{4\left(1-\theta^{*}\right)}+b_{L}-\right.\right.$ $\left.\left.k b_{H}\right)+\beta k \frac{\left(1-b_{H}\right)^{2}}{4}\right)$ is strictly increasing since $\frac{\partial \pi}{\partial \theta^{*}}=q_{L}\left(k b_{H}-\right.$ $\left.b_{L}\right)=c_{H}-c_{L}>0$.

C. Over $\left[\frac{1+b_{H}}{2}, \frac{1+b_{L}}{2}\right), \pi\left(\theta^{*}\right)=q_{L}\left(\left(1-\theta^{*}\right)\left(\frac{\left(1-b_{L}\right)^{2}}{4\left(1-\theta^{*}\right)}+b_{L}-\right.\right.$ $\left.\left.k b_{H}\right)+\beta k\left(1-\theta^{*}\right)\left(\theta^{*}-b_{H}\right)\right)$ is a strictly concave function since $\frac{\partial^{2} \pi}{\partial \theta^{* 2}}=-2 \beta k q_{L}<0$. It takes its maximum value at $\theta^{*}=$ $\frac{1}{2}+b_{L} \frac{\lambda(1+\beta)-1}{2 k \beta}$ which is $<\frac{1+b_{L}}{2}$ since $\lambda<\frac{1+k \beta}{1+\beta}$. It is now straightforward to conclude that there is a unique LCSE at $\theta^{*}=\frac{1}{2}+b_{L} \frac{\lambda(1+\beta)-1}{2 k \beta}$, where the constraint (IC2) is the only one to be binding.

Proof of Proposition 4: The proof is made through two parts.

1) Part $1:$

- In Zone I, where $\lambda \geq \hat{\lambda}, \bar{\theta}^{*}-\theta_{H}=0$.

- In Zone II, where $\tilde{\lambda} \leq \lambda \leq \hat{\lambda}, \bar{\theta}^{*}-\theta_{H}$ has the same sign as:

$L(\lambda)=\frac{1}{2} \frac{k b_{L}(\beta+1)-\lambda b_{L}(k+\beta)+k \sqrt{-k-\beta+k \beta+b_{L}^{2}-k b_{L}^{2}+\beta b_{L}^{2}+k^{2}-k \beta b_{L}^{2}}}{k(k+\beta)}$

which is a decreasing function of $\lambda$. We easily check that $L(\lambda=\hat{\lambda})=0$. Accordingly, $\bar{\theta}^{*}-\theta_{H}>0$.

- In Zone IV, where $1 \leq \lambda \leq \bar{\lambda}, \bar{\theta}^{*}-\theta_{H}$ has the same sign as $\frac{1}{2} b_{L} \frac{\lambda-1}{k \beta}$ which is positive.

- In Zone III, where $\bar{\lambda} \leq \lambda \leq \tilde{\lambda}, \bar{\theta}^{*}-\theta_{H}$ has the same sign as: $\lambda(k+\beta)-k-k \beta$ which is increasing w.r.t $\lambda$.
Accordingly, from the continuity of $\bar{\theta}^{*}$ w.r.t $\lambda$ in the set $\left[1, \infty\right.$, it obtains that $\bar{\theta}^{*}-\theta_{H}>0$.

2) Part 2:

- In Zone I, where $\lambda \geq \hat{\lambda}$, we have $\bar{P}_{1}-P_{H}=0$.

- In Zone II, where $\tilde{\lambda} \leq \lambda \leq \hat{\lambda}, \bar{P}_{1}-P_{H}$ has the same sign as $I(\lambda)=b_{L}(k(1+\beta)-\lambda(k+\beta))+$ $k \sqrt{-k-\beta+k \beta+b_{L}^{2}-k b_{L}^{2}+\beta b_{L}^{2}+k^{2}-k \beta b_{L}^{2}}$ which is a linear decreasing function of $\lambda$. We check that $I(\lambda=\hat{\lambda})=0$. Accordingly, $\bar{P}_{1}-P_{H} \geq 0$.

- In Zone III, where $\bar{\lambda} \leq \lambda \leq \tilde{\lambda}, \bar{P}_{1}-P_{H}$ has the same sign as $\frac{H(\lambda)}{2(k-1)\left(-\beta+k \beta-b_{L}(\lambda-1)(\beta+1)\right)}$ with:

$$
\begin{gathered}
H(\lambda)=b_{L}^{2}(\beta+1)(k+\beta) \lambda^{2}+b_{L}\left(-k-\beta+b_{L}+k \beta\right. \\
\left.-3 k b_{L}+\beta b_{L}+k^{2}-5 k \beta b_{L}-2 k \beta^{2} b_{L}\right) \lambda \\
+\left(k^{2} \beta^{2} b_{L}^{2}-k^{3} \beta+k^{2} \beta b_{L}^{2}-k^{2} \beta b_{L}+3 k^{2} \beta-k^{2} b_{L}+2 k \beta b_{L}^{2}\right. \\
\left.+k \beta b_{L}-3 k \beta+2 k b_{L}^{2}+k b_{L}-\beta b_{L}^{2}+\beta-b_{L}^{2}\right) .
\end{gathered}
$$

It is straightforward that the denominator $2(k-$ $1)\left(-\beta+k \beta-b_{L}(\lambda-1)(\beta+1)\right) \quad$ is positive from Assumption H.1. Note that $H(\lambda)$ is a convex function and $H(\lambda=\bar{\lambda})=\beta(k-1)^{3}\left(b_{L}-1\right) \frac{\beta+\beta b_{L}+1}{\beta+1}<0$. Necessarily, one of the two roots of $H(\lambda)$, which we call $\lambda_{c}$, is higher than $\bar{\lambda}$. Accordingly, when $\bar{\lambda} \leq \lambda \leq \lambda_{c}, H(\lambda) \leq 0$ and when $\lambda \leq \lambda_{c}$, $H(\lambda) \geq 0$.

- In Zone IV, where $1 \leq \lambda \leq \bar{\lambda}, \bar{P}_{1}-P_{H}$ has the same sign as $\frac{F(\lambda)}{\lambda b_{L}(\beta+1)-b_{L}-k \beta}$, with $F(\lambda)=-b_{L}^{2}(\beta+1) \lambda^{2}+$ $b_{L}\left(-k+3 b_{L}+2 \beta b_{L}\right) \lambda+\left(\beta k^{2}-\beta k b_{L}^{2}+k b_{L}-\beta k\right.$ $\left.-2 b_{L}^{2}\right)$. Recall that in Zone IV, since $\lambda \leq \bar{\lambda}$, we obtain:

$$
\lambda b_{L}(\beta+1)-b_{L}-k \beta \leq \frac{1+k \beta}{1+\beta} b_{L}(\beta+1)-b_{L}-k \beta .
$$

The RHS of the inequality is equal to $k \beta\left(b_{L}-1\right)<0$. Thus, the denominator $\lambda b_{L}(\beta+1)-b_{L}-k \beta<0$. Note that $F(\lambda)$ is a concave function. We check then that $F(\lambda=1)=$ $\beta(k-1)\left(k-b_{L}^{2}\right)>0 \quad$ and $\quad F(\lambda=\bar{\lambda})=-k \beta\left(b_{L}-1\right)$ $\left(\beta+\beta b_{L}+1\right) \frac{k-1}{\beta+1}>0$. Since $1 \leq \lambda \leq \frac{1+k \beta}{1+\beta}$, it obtains that $F(\lambda)>0$. As a result, $\frac{F(\lambda)}{\lambda b_{L}(\beta+1)-b_{L}-k \beta}<0$.

\footnotetext{
${ }^{46}$ They also intersect in another solution which is implausible since it is larger than $\frac{b_{L}+1}{2}$.
} 